\title{
Proposing a Generalized Darwinism-Based Theory of Evolutionary Marketing Research for Non-Linear Marketing Contributions: Theoretical Analysis, Conceptual Framework and Research Agenda
}

\author{
Wael Kortam \\ Professor of Marketing \\ Business Administration Department \\ Cairo University, P.O, Box 12631, Egypt \\ E-mail: wael.kortam@foc.cu.edu.eg \\ Ghada Gad \\ Assistant Lecturer at the Business Administration Department \\ Canadian International College - CIC, Egypt \\ E-mail: ghada_gad@cic-cairo.com
}

Received: March 19, 2019

Accepted: April 6, 2019

Published: September 12, 2019

doi:10.5296/wjbm.v5i2.16091

URL: https://doi.org/10.5296/wjbm.v5i2.16091

\begin{abstract}
This research aimed to formulate an innovative conceptual model of why and how the marketing research creed and process should evolve and proceed to live up to the emerging high ends of marketing in theory and practice. The new conceptual framework adopted an interdisciplinary approach through striving to build an evolutionary marketing research theory that is triggered by a generalized Darwinism intellectual paradigm with special emphasis on fulfilling nonlinear marketing contributions as a highly desirable and yet demanding modern marketing destination. Apart from substantive theoretical analysis of a widely relevant variety of academic literature, the conceptual model was further grounded on exploratory evidence on marketing research panels as arguably creative and insightful empirical context in the form of analysis of secondary data and qualitative research on the world class adoption of panels by best practices of the global marketing research industry. The paper concluded with a detailed road map for a research agenda through three formulated
\end{abstract}




\section{Macrothink}

World Journal of Business and Management

ISSN 2377-4622

2019, Vol. 5, No. 2

research propositions and a planned research methodology for rigorous real data-driven testing and subsequent refinement of the proposed intelligentsia of the conceptual model.

Keywords: Generalized Darwinism, Evolutionary marketing research, Non-linear marketing, Panels, Meta-analysis 


\section{Introduction}

The main importance of this research lies at contribution to theory development in marketing research. as argued by the conceptual framework marketing need to improve its scientific credentials as an academic discipline to which The three main streams of this research will aim to make a significant improvement of marketing as a science; The dependent variable which is nom-linear marketing agenda is argued to improve the integration academic understanding of marketing phenomena insights and outlook, configuring and devising generalized Darwinism as an independent variable and evolutionary marketing research as an intervening variable should be expected to help in reflecting a new understanding of how the marketing research process can considerably boost the scientific status of marketing through full filling the above indicated non-linear marketing agenda, and this research is also interested on the marketing practice level to help in bridging the gap between marketing theory and practice. The reconciliation essence of non-linear marketing should create streams of marketing research that probably comply, revisit and blur marketing boundaries to create more advanced, yet down-to-earth marketing knowledge. Using the philosophy of generalized Darwinism and evolutionary marketing research are argued by this research to accomplish significantly high level of relevant and applicability leading to a more practice-theory of non-linear marketing.

\section{Theoretical Background}

The critical and analytical literature review would cover three main research streams and venues; mainly:-Concept of Darwinism and its marketing applications, An evolution theory of marketing research as the conceptual drive of this research, Non-linear marketing as a universal agenda underlying theory and practice.

\subsection{Generalized Darwinism / Marketing Perspective}

In the biological world, evolution occurs over time through the key Darwinian mechanisms of variation (of genotypes), selection (of the consequent phenotype) and replication or inheritance (of the underlying genotype), where the genotype is defined as the information inherited by an individual from its parents (i.e. genes), which has the potential to be transmitted to future generations. The phenotype, in contrast, is the developmental expression of the genotype in a particular environment, as manifest through the physical characteristics of the organism (Breslin, 2010).

The statue of Charles Darwin, neglecting the cove where the scientist ventured aground on Chatham, now san Cristobal, the foremost easterly of the Galapagos islands rouses the ways in which evolutionary theory can contribute to our understanding of social sciences in general and marketing theory in particular (Barnett, 1996 and Vollmer, 2010).

It appears barely possible that insight observation of finches, mocking birds and tortoises may change the way researchers think about the world, but in the 19th century it happened. The Galapagos, 700 miles from the mainland of Ecuador, contain Flora and Fama that contrast from those of the rest of the world and differ, but less, from island to island. Darwin was to secure the method by which this design came about. Evolution is a process with three stages 
or phases: - variation, selection, and replication. Changes happen, a few of these changes yield advantage, and such changes tend to be duplicated in subsequent generations. The additional outcome coming to in its implications that Darwin hesitate to distribute his ideas that designs of extra ordinary complexity and effectiveness can be accomplished without the help of one single superior experts of design. Designs can develop beyond the comprehension of any person (Chiou \& Pan, 2008; Saad \& Gill, 2000). That understanding and the mechanics of variation, selection and replication are relevant to numerous issues other than the origin of species. By analogy, advances marketing theory and practice have created as a result of the variation that comes from experiments and tests in products and marketing methods, the selection developed by customers and capital markets of adaptation and innovations that add value (and the ejection of those that don't) and finally the replication by competitors of strategies that succeed (Daniels \& Martin, 1999; and Gunn, 1969).

Evolutionary thinking has made small progress in social sciences with uncommon reference to economics, business and marketing and experienced incredible resistance in other social sciences.one source of trouble is the character and token of those who favor such mental and intellectual extension and theoretical universality. Herbert Spencer, the 19th century philosopher of social sciences who coined the expression "survival of the fittest" appears an outrageous figure in modern eyes; however he was highly persuasive in his time. Spencer saw social evolution as a process of progressive advance throw natural selection which is an idea created by eugenicists, who supported selective breeding to develop the quality of human stock / inventory. Eugenics was comprehensively ruined when the Nazis took the argument to dangerous extremes (Kundsen, 1999; and Mulcohy, 2003). Indeed nowadays, the idea that human behavior might have organic organs is corrupted by those fascist and racist associations. When EO Wilson the recognized biologist connected the experiences he had picked up from the study of communities of ants to human social organization. His lectures were picketed and he was drenched with water at a meeting of the American association for the advancement of science. But the illustrating opponents had small understanding of the focuses at issue to describe evolution as "Survival of the Fittest" is in a sense exact but also significantly misleading. The process of evolution is one of adaptation rather than improvement (Satter, 2009; Matthews, 1984; and Marks, 2001). On the other side of the contention presented by this research, an emerging state-of-the-art, critical and innovative evolutionary viewpoint on present and modern marketing research thought could be formulated to lead to designing the marketing research process as a scientific transformation and change process as proposed by Kortam (2006). This proposed process is seen as concerned with looking at and positively dealing ill-informed marketing issues and analytical gaps in marketing theory and practice. Based on that vision, the marketing research process can be, arguably, conceptualized as comprising of three fundamental continuous phases.

\subsubsection{Darwinism Evolution Conceptualization in the Socio-Cultural Arena}

The concept of generalizing Darwinian principles was developed in the broader field of socio-cultural evolution (Breslin, 2010), and maintains that Darwinian concepts can be broadened from the domain of biology (Lewontin, 1970) and applied to all forms and levels of life (Hodgson, 2002). 
A really evolutionary approach to economic theorizing had been isolated amid most of the 20th century, after that it has increased again over the last three decades, a methodological discussion has been activate almost whether it makes sense to construct such an approach upon concepts borrowed from Darwinian biology (Schubert, 2012), A meta-theoretical framework has been proposed by Geoffrey Hodgson for describing and analyzing economic change of a generalization of the fundamental Darwinian notions of variation, selection and replication to the socio-economic field (Hodgson, 2002; Hodgson \& Knudsen, 2006a, 2010a; Aldrich et al., 2008; Schubert, 2012 ). That approach attempts to examine the metaphorical usefulness of "evolution" or "Darwinism" in general and of these three Darwinian principles in particular to understand specific processes of socio-cultural and particularly economic evolution (Campbell, 1965; Winter, 1964; Nelson \& Winter, 1982). The role of Darwinians' implications thought in reshaping economics, for the way evolution is conceptualized in the socio-cultural field, and for the specification of the essentials of evolutionary economics proper (Schubert, 2012), A lot ambitious program has encouraged a vital discussion, during which it has face a persistent skepticism (Nelson, 2006; Cordes, 2006, 2009; Vromen, 2007, 2008, 2010; Pelikan, 2010; Levit et al., 2011; Andersson, 2011), the time has come to test the logical potential of this meta-theoretical framework to evolutionary economics. So distant, this has been done in the field of industrial and firm change (Bünstorf, 2006; Murmann, 2003) and organizational change (Stoelhorst, 2009; Breslin, 2011).

\subsubsection{The Applied Evolutionary Theory of Policy-Making}

General focus in an evolutionary account of policy-making has increased in recent years (Rubin, 2002; Witt, 2003; Wilson \& Gowdy, 2010; Schubert, 2012); by enhancing its practical relevance by developing sound policy recommendations and the economic approach to policy-making should be informed by evolutionary theorizing, for the latter can improve policy advice by helping decision-makers "understand the large-scale and long-run consequences of economic policies" (Wilson \& Gowdy, 2010).Second, it could make sense of problems that are misconceived in neoclassical accounts of policy-making, such as the complex relationship between individual and collective welfare, and the persistence of mal-adapted irrational products of evolutionary processes, such as dysfunctional institutions (Whitman, 1998). In many researches GD acting as a focusing device that lead scientists in their search for normative criteria and policy objectives that are both compatible with an evolutionary world-view in their own right. It may induce them to construct, if implicitly, analogies between biological criteria of success or "fitness" and cultural concepts of welfare, lead them to narrowly focus on the systemic "quality-of-species", rather than the individual quality-of-life level of welfare, and it may generate policy advice that looks arbitrary for it is unclear what justifies the choice of its fundamental values.

What Generalized Darwinism offers is essentially a deductive, top down methodology (Levit et al., 2011). Scientists feel compelled to look at economic phenomena through the analytical lens provided by the "Darwinian triple" of variation, selection and replication, and to bend their theoretical concepts so that they fit into the scheme. Not only positive economic theorizing can be misguided by biological analogies (Schubert, 2012). 
As a contribution of several co-authors, Geoffrey Hodgson has influenced by evolutionary scholars such as Campbell (1960, 1965), Dawkins (1983), Lewontin (1985), Dennett (1994), and in particular Hull (1988). On a basic methodological level, Generalized Darwinism claims the following;- All social science ought to be committed to detailed, cumulative and causal explanations instead of functional just so-stories, A particular causal explanatory rationale applies to all evolutionary forms: All such forms in both the natural and the socio-cultural realm (a) share the same fundamental ontological structure, (b) which is, more particularly, one that can only be described by the Darwinian scheme of an energetic interplay of variation, selection and replication. In terms of heuristics, the Darwinian scheme is the only system that can be utilized to show these processes (Schubert, 2012).

\subsubsection{Generalized Darwinist Approach to Study Socio-Economic Change (Breslin, 2010)}

Many scholars have explored the possibility of using the principles of Darwinism to study socio-economic change not only studying the organizations (Breslin, 2010); both at the macro-level of populations of organizations (Brittain \& Freeman, 1980; Hannan \& Freeman, 1977) and also, at the micro-level of organizational change (Aldrich 1999; Campbell, 1965; Nelson \& Winter, 1982).

Generalized Darwinists argue that at a general level of abstraction a core set of general Darwinian principles of variation, selection and replications can be used to describe evolution within a variety of domains (Campbell, 1965; Hodgson, 2003; Hodgson \& Knudsen, 2004; Schubert, 2012), including biology, psychology, policy making, culture and economics. In this manner, while the details of socio-economic evolution may be different from biological evolution, the concept of Generalized Darwinism can be used as a starting point for the development of theory in both. (Breslin, 2010) argued that, These huge developments have been obstructed not only because of disagreement between the scientists themselves over the conceptual and applying approaches taken, but more widely by criticisms from a diverse range of established scientific traditions within economics and organization science (Buenstorf, 2006; Cordes, 2006; Nooteboom, 2006; Witt, 2004).

The concepts of 'replicator' and 'interactor' in Generalized Darwinism are substituted for the genotype and phenotype in biological evolution (Dawkins, 1976; Hull, 1988), where the replicator is defined as anything in the universe of which copies are made, such as genes in the biological world (Breslin, 2010). Interactors are defined as entities that interact as a cohesive whole with their environment in a way that causes differential replication of these elements (Hull, 1988). Using this generalization, Hull (1988) outlined selection as a two-step process involving the direct replication of an encoded instruction set, and the direct interaction of the entity of interest with the environment in a way that causes differential replication (Breslin, 2010).

It is important to stress that Generalized Darwinism is not based on making analogies between biological and socio-cultural evolution, but on applying the abstracted mechanisms of variation, selection and replication, alongside the concepts of the replicator and interactor to all evolutionary systems (Breslin, 2010). 
It was seen over that a number of past studies in socio-economic change show up to share numerous features with the idea of Generalized Darwinism, in that many utilize the mechanisms of variety, selection and retention as the beginning point for developing theory, and a few moreover embrace the replicator-interactor distinction. A few advances has been made in applying the approach to areas of study such as entrepreneurship, organizational differences, population biology, organizational change, organizational learning and innovative advancement (Aldrich, 1999; Breslin, 2008; Brittain \& Freeman, 1980; McCarthy, 2005; Mokyr, 2000; Murmann, 2003). Past research can moreover be broadly classified into studies which focus on the level of populations, on the level of organizations and multi-level co-evolutionary studies. In any case, what remains to be resolved over not only the domain of socio-economics, but more broadly inside social science, is an concurred agreement regarding the approach taken. Looking in more depth at a few of these areas, the potential to be picked up from utilizing a Generalized Darwinist approach can be examined (Breslin, 2010).

Darwin himself suggested the idea of generalizing the Darwinian principles to apply the evolution of social entities, however misunderstanding; poor presentation and misleading application have hampered the realization of the strong and powerful potential longstanding of the idea (Aldrich et al., 2008). On the other hand some critics confuse generalization with analogy; they assume that generalizing Darwinism involves biological reductionism. On the other hand, the thought of generalizing Darwinism to socio-economic evolution challenges the longstanding thought among social researchers that social and natural phenomena ought to be totally apportioned, that social researchers have little to learn memorize from science, and vice versa. A generalized Darwinism is reliable with the idea that human society is inserted within the natural world and depends upon it for its survival (Aldrich et al., 2008).

Some researchers argued that a generalized Darwinism supports important, non-vacuous recommendations that are profoundly important to the advancement in human societies, such as customer bases like the systemic logical marketing research process (i.e. evolution marketing research). Darwinian thoughts have vital suggestions for social researchers concerning the rationality and mind of human specialist's (e.g marketing researchers). Assumptions concerning human specialists must be reliable with researchers understanding of human evolution. Darwinian advancement includes the improvement, maintenance and choice of the information concerning adaptive solutions to survival issues faced by organisms in their environment. Darwinism continually raises questions of causality and requires clarifications of origin. This applies in specific to the dispositional programs behind human thought and behavior (Aldrich et al., 2008) for example the phases of marketing research evolution. Over all, Darwinism by itself is deficiently to provide full and complete answers, but it gives a common framework in which extra and context specific clarifications may be placed such as evolution marketing and non-linear contributions. Its assist value depends on extra and extensive work by evolutionary marketing research and non-linear marketing solutions. As hodgson and knudsen mentioned that populations of varied and replicating entities are found in human society and nature, it is a complex evolving system such as marketing research industry to complete the explanation Darwinism which has been used in 
spite of principles of Darwinism for complete explanation that are not sufficient on their own like marketing research system. (Hodgson et al., 2006). The complex systems considered here include populations of entities of particular sorts. Individuals of each sort are comparative in key respects, but inside each sort there's a few degree of variety, due to genesis, circumstances or both (Hodgson et al., 2006).

In generalizing Darwinism to social evolution, we are tending to populations of social entities such as traditions, rules, schedules and institutions. The idea of self-organization may be very important in making a difference to clarify in a few cases how individual entities create, but we still require a Darwinian theory to start to explain the evolution of the full population of such entities. Self-organization alone cannot clarify the adaptation and differential survival of self-organized outcomes. Human intentionality is exceptionally imperative within the social circle. People have interesting capacities for prefiguration and consideration. Human social interaction moreover includes the imputation of such powers to others with whom we associated. There's nothing in Darwinism that avoids or belittles human intentionality, prefiguration, pondering, and choice. What Darwinism requires is that they as well ought to be subject to causal clarification (Hodgson et al., 2006).

Hodgson et al. (2006) also mentioned about Concerning the Lamarckian inheritance of obtained characteristics, most scientists of biology dismiss such a possibility within the organic domain, and the Lamarckian portrayal is itself problematic. Even if procured character legacy did happen on another planet or in social evolution, it would not rule out Darwinism, which is essential to clarify why obtained disabilities or injuries are not inherited. Darwinism and Lamarckism are not one or the other rivals nor alternate extremes. On the off chance that Lamarckian inheritance did happen, at that point Darwinian principles would be required to total its clarifications. Subsequently, the case for utilize of the 'Darwinian' name is much more grounded than the 'Lamarckian' one, indeed in the social setting. The core analysis argued by Grandinetti (2018) on his research has focused on Darwinism never the less Lamarckism stands as a burial holistic approach that have contrasted or interweaving with evolution and also in the industry of the organizational evolution. Despites the profound differences between two prospective on revolution; Darwin emphasizing step-wise evolution while Lamarck highlighting piece-wise evolution. Yet Darwinism evolution reflects a gradual process vertically while Lamarckian evolution represents a horizontal evolution, with a view toward remaining within the gradual time. Phased evolutionary perspective on marketing research, the phase's evolutionary perspective on marketing research, the phases and process that Lamarckism adopts to explain evolutionary discontinuity in the evolution of organization entities and process like marketing research systems and process will not be considered by this research as a new different frontier for further research and conceptualization of evolution marketing research.

In whole, as long as we are tending to a population of replicating entities, at that point social evolution must be Darwinian, whether or not self-organization, human purposefully, or Lamarckian inheritance are included. As long as there's a population of replicating entities with shifting capacities to survive, at that point Darwinian evolution will occur. Social evolution bargains with populaces of substances, counting traditions and social institutions 
that compete for rare assets. In like manner, we accept that social evolution is Darwinian. This isn't essentially a matter of analogy; it may be a partial description and investigation of reality. Social evolution is Darwinian by ideals of (social) metaphysics, not (biological) analogy. However, the ontological case for expanding Darwinism to social evolution refers to exceptionally broad ontological communalities, not to things of detail. To repeat: biological evolution and social evolution are exceptionally diverse with respect to details. Nevertheless, All things considered, Darwinian modes of explanation are essential to address the ontologies of advancing populations, in both the biological and the social domains. However, the idea of a generalized Darwinism itself gives no alternative to a detailed explanation of the particular rising properties and forms at the social or natural levels. Darwinism does not itself give all the necessary causal mechanisms and clarifications for the social researcher, nor forestall the elaborate extra work of particular examination and detailed causal clarification within the social sphere (Hodgson, 2001). Darwinism is unavoidable but this does not mean that the core Darwinian Theory is sufficient to clarify the forms of social evolution like evolution marketing research process. Darwinian standards give a common explanatory framework into which specific explanations and empirical subtle elements have to be put (Hull, 1973) through empirical research domains like panels and meta-analysis. A generalized Darwinism cannot itself donate researchers a full, detailed clarification of evolutionary processes or result. It is more a meta-theoretical than a complete theory in which necessitate devising meta-analysis for integrating theoretical gaps that may arise by the sole dependence on Darwinism theory of panels-based marketing research reports the evolutionary marketing research constructs. For the evolutionary social sciences, as somewhere else in marketing research, Darwinian general standards are essential but not sufficient.

2.1.4 A Generalized Darwinism as a Framework to Study Competition and Industrial Evolution (Buenstorf, 2006)

Buenstorf mentioned that Darwinist heuristics have motivated critical insights by evolutionary economists, enabling them to approach economic phenomena in inventive ways. Darwinist metaphors additionally give effective explanatory devices. In expansion, the discussion of Universal Darwinism can be a stimulating mental work out of exploring abstract parallels between evolutionary forms in different domains, which may help evolutionary economics in its journey for a unified analytical framework. The concern with the generalized Darwinist system communicated in this paper is that the attempts of fitting evolutionary theorizing in economics into a system as well near to evolutionary biology risks losing locate of critical perspectives of economic processes.

Besides, it may actuate us to acknowledge excessively stylized and possibly non-falsifiable How valuable is generalized Darwinism as a framework to consider competition concepts that contribute small to the understanding of concrete economic phenomena. Signs of these risks were distinguished within the schedule and inheritance concepts proposed as parts of the endeavor to form the generalized Darwinist system operational for developmental economics. As an elective to the 'top-down' approach of forcing an unique system on developmental economics, a 'bottom-up' approach has been pushed that combines hypotheses of learning with empirical endeavors to distinguish the point by point forms fundamental the 
procurement and exchange of information inside and over real-world organizations. Significant endeavors of this kind are as of now being made, in portion by researchers who have a place to the developmental economics community. Seeking after this elective approach in addition is in line with another Darwinist legacy that's beneath emphasized in developmental economics. Darwin was an empiricist who did not begin from unique philosophical standards but from the prove he confronted. Science has since been an empirical science, and typically one of the foundations of its huge victory within the 20th century. Maybe evolutionary economics would be well served by being more "Darwinist" in this particular sense. There could be theoretical support out of this argument for using panels as fixed samples to develop competitive superiority, thriving customer values and uncontestable marketing know-how to develop new competitive advantages for emerging industries and evolving markets through a different mind-set of competitive themes. The extracted adoption of artificial intelligence relying on big data (cross sectional and longitudinal ) and advanced analytics to reveal evolutionary insights of existing patterns and emerging trends across longer and longer time horizons and phased time intervals is another expression of the Darwinism framework spill over interpretation of the full-scale and new frontiers lying a head of evolutionary marketing research.

\subsection{Evolution Marketing Research / A core Essence}

The twentieth century given the marketer with riches of modern primary marketing investigates tools and methods. Progresses within the ranges of quantitative and qualitative research have made it much simpler for the marketer to way better get it the marketplace, the competition, and, most vitally, the client (Jones, 2006; Drozdenko \& Drake, 2002).

In an environment where customer relationship management ( CRM) or add up to customer relationships (Hax \& Wilde, 2001) is the ruling paradigm, marketers got to accumulate as much relevant data on the customer as is practically and ethically possible. This data require collecting, verified and turned into relevant information. The information at that point must be analyzed, translated, and changed over into intelligence. In turn, the intelligence then needs to be comprehensively connected to the objectives and needs of the organization, subsequently making it actionable. By comprehensively taking after this process marketing not only becomes more credible and usable, but moreover it gets to be more accountable (Rosenwald, 2004). Within the past, marketing research has been seen by many companies as an action to some degree evacuated from the action of deals and marketing (i.e., staff service department). Indeed by scholastics it was treated separately from the marketing mix situation often without a clear clarification of its part. Marketing research was frequently called upon to degree the potential of proposed new products (frequently after the plan had been completed and prototypes created), to measure results, to unravel day to day marketing problems, sometimes to assist in arranging and occasionally to point an unwelcome finger at those who committed mistakes that depleted benefits and made losses (Kortam et al., 2012).

Haring 2016, has made a historical evolution analysis of the main marketing research techniques since 1920 to 2016. The key implications of this paper to the theme of the research is that, it has reviewed the methodologies, rationale and contributions of most 
commonly used marketing research techniques at the critical steps of measurement and data collection, sampling and data analysis. Yet, the paper failed to come up with an explanation of the marketing developments that has led to the adoption of those techniques where the appropriate response to those prevailing and emerging marketing forces.

from a different perspective (tadajewski et al., 2015) has aimed to make an examination of how far the evolution of marketing research in practice has contributed to human well-being and welfare their critical reviews probably and fairly revealed that the stereotypical adoption of marketing research processes with special emphases on consumer-oriented research has drastically fallen short of visualizing the human well-being agenda as far as social equity and fair distribution of globalization income are concerned. Nevertheless the paper declined to suggest any venue for future innovation and liberalization of marketing research to help achieve that agenda.

Another example of investigating marketing research as an evolutionary process was that by (filles, 2011) through making a historical account based on a longitudinal review of arts marketing research showing how it has evolved from an application of marketing based on traditional principles into a recognize research domain based on critical and creative approaches. (Filles, 2011) highly recommended that the rigor, depth and richness of marketing research within other context needs much further exploration and that is only a very small number of assessment of state-of-the-art marketing research have been carried out. The contextual limitation as even admitted by Filles himself is a clear short coming of the contribution of this paper to understanding the evolution of marketing research.

Like filles (2011; morosan et al., 2014) have end to provide a domain expression of the evolution of hospitality marketing research over the past 25 years. The main differences is that this study looked at the main research paradigms that will contextual used to investigate the main stream unique aspects of hospitality industries. The contextual limitation remains the main shortcoming of using this study for broad purpose modeling of evolution marketing research.

A more predictive paper of marketing research evolution was made by (Hausier, 2007) who has foresight of the revolutionary role of big data and analytics of marketing. (Hausier, 2007) mad a strong prophecy that marketing research in the 21 century would focus on using technology specially data mining and marketing analytics to make an advanced mix of focused quantitative and qualitative techniques. The paper has argued that marketing analytics would be the dominant and standard marketing research tool in the 21 century. The clear reservation of this paper that it has over emphasized the marketing research toolkit while down playing the strategies agenda changes for marketing research. Thus, getting back to the long standing sin of over estimating (how) and under estimating the (why) of marketing research as an outcome of infatuation of technology. (Layton, 2017) has demonstrated that his understanding of meaning of marketing constraints has drastically evolved and changed over time. Again this is further proof that marketing research has continues evolution a cross time even within the mindset of one research thus, helping to improve time developed rich and fresh perspectives on even one's comprehensive of 
marketing phenomena and variables.

Finally another implicitly relevant paper is that by (Nunan \& Doremica, 2013) which focused on the ethical privacy considerations of using big data. Since big data is expected to play an important role in the configuration of an evolutionary phased marketing research process that is grounded on Darwinism principles, any barrier (ethical or otherwise) to accelerated adoption of big data should be carefully considered and (hopefully) conceptually removed. The main differences argued by this research from above studies lies in the premise that those studies were either examining the evolution of marketing research from within and beneath its river of techniques or through a view from a bridge based on its outside context, while this research looks from the river of internal marketing research steps and the over view of the bridge of marketing research agenda and contributions devising meta-analysis to transcendence through the various internal marketing research processes and external marketing research time, industry and universe contexts.

From another perspective (kortam, 2006) argued by a research paper, an emerging state-of-the-art, critical and innovative perspective on modern marketing research thinking would be devised to lead to configure the marketing research process as a scientific transformation process ( Blankenship \& Breen 2000; Mc Daniel \& Gates, 2000; Churchil, 1995, and Shao, 2002). This proposed process is seen as examining and positively handling marketing research issues and analytical gaps between theory and practice. According to this point of view, the marketing research process can be arguably conceptualized as three main consecutive phases as per (Kortam, 2006); First, an encoding of concept phase pointing to encode marketing problems and/ or opportunities into scientific terms in the form of marketing research questions/ hypotheses. The quintessence of this encoding stage through carrying out exploratory problem/ opportunity definition activities to formulate research hypotheses or questions. The most concern here should be on the comprehensive encoding of all the concepts constituting the specific and particular aspects of the problem/opportunity under research. Second, an application of marketing research methods phase which looks for rigorously and verifiably implement the scientific process and adopt tools of marketing research. The most concern of this stage is to reach scientifically-grounded marketing solutions to solve encoded marketing problems or encoded opportunities seizing. The main concern of this stage is hung upon the strict and efficient systematic conduct of the conclusive marketing research activities of sampling design and plan, development of measurement scales, data collection and finally preparation and data analysis. Third, A decoding to context phase, which basically includes translating scientific marketing solutions to defined problems and/ or opportunities in to actionable marketing decisions and policies. The conclusive marketing research activities of this stage are those of interpretation of analyzed and reporting these interpretations with a view toward expanding and advancing research recommendations and findings. The most concern of this phase is to come up with insightful, quick, far reaching, precise and creative interpretations of findings that are valuable within the context in which marketing organizations encountering such problems/opportunities work. As a wrap up, this configuration by (Kortam, 2006) contends that the value added of marketing research rests on a comprehensive encoding of marketing 
research inputs, a rigorous application of marketing research process and a reasonable, realistic and action-oriented interpretation and translation of marketing research outputs.

Such evolutionary synergy-oriented systems' view point and perspective of marketing research activities is argued to help in making marketing research more adaptable and thus more profitable to particular settings such as generalized Darwinism highlighting survival of the fittest of intellectual information and knowledge through the phases of variation, selection and replication in this way emphasizing vigor of marketing intelligentsia which applies only to knowledge and declining the disrespect of any biological superiority (Kask, 2013; and Kortam et al., 2012).

\subsection{Non-Linear Marketing/ A Research Platform}

Non-linear marketing is a universal philosophy of marketing thinking and doing that seeks to combine the disciplines and areas of contextual marketing and holistic marketing with a view toward a new step in improving the quality and position of making as a science and bridge the gap between marketing theory and practice (kortam, 2017). Contextual marketing refers to purposely endeavor to produce new marketing knowledge through absolute relevant response to the different contexts within which marketing phenomena and variables are investigated and managed (Kenny \& Marshall, 2000). On the other hand, holistic marketing struggling for introducing a revolutionary marketing-driven and led to total business solutions for all kinds of organizational and institutional settings, and platforms (Choi et al., 2015). This portfolio of formidable and much needed impacts can only happen through focusing on and employing a nonlinear marketing philosophy that explicitly advocates and prescribes a marketing universe that embraces initiates and perpetuates a highly matured and insightful venue of marketing thinking and doing (kortam, 2017). These spots should be expected to generate a collectively and carefully blended contextual and holistic marketing research and practices that can assume a mainstream, a critical or an explosive essence and form. The integrated synergy among these three conceptual and practical venues could be claimed to improve the scientific credentials of the discipline of marketing and simultaneously bridge the gap between marketing theory and practices (Kortam, 2017).

The foundation of nonlinear marketing thinking and doing is laid on three philosophical postulates of marketing underlying rationales (Kortam, 2015; Priesmeyer, 1992; Hibbert \& Wilkinson, 1994; Bischi \& Baiandi, 2015; Follmer, 1974; Bonanno \& Zeeman, 1985; Schaninger et al., 1980; and Sheth \& Sisodia, 2015):

1) A Marketing phenomenon can never be expressed as a straight line.

2) A Marketing insight can never be gained at one point.

3) A marketing outlook can never be foreseen relying on a sharp angle.

That contextual marketing expresses the need for and proposition of new responsive marketing knowledge to change marketing context (Kortam, 2017). From a different perspective, holistic marketing expresses the need for and propositions of total marketing-driven business solutions. This research called for discovering new holistic 
approaches to rethink marketing totally alongside remaining faithful to context-generated new marketing knowledge (Groves et al., 2008; sheth \& sisodia 2015; polonsky et al., 2005; and keller \& kotlar, 2006). In a conclusion of the above research, that the main changing marketing context that necessitates and promises new marketing knowledge are namely; 1) country/culture, 2) customer base, 3) market segment, 4) industry/organization, 5) technology, 6) product/service/person/idea/place, and 7) time (Rust, 1982; Christen et al., 1997; Tax et al., 1998; Pros \& summers, 1975; and Kenny \& Marshall, 2000). On the other parallel front, the more limited literature on holistic marketing emphasized a number of overriding factors on drive total marketing-based business solutions including in the main; 1) profit/ cost/ firm value, 2) knowledge, data, information/ intellectual capital, 3) brand, 4) relationship equity and intimacy, 4) social values and contributions, 5) planned organizational change and development and 6) marketing revolution (Vincent, 2002; steenkamp et al., 2000; and Barius, 1994; Kortam \& mahrous, 2011). (Kortam, 2017) highly recommended that articulation of proposed universal philosophy of non-linear marketing should start by acknowledge the existing boundaries of marketing thinking and doing, There is a number of boundaries on bonders of scientific and professional norms that are widely naturalistic to marketing scholars and practitioners namely; 1) customer must be focal, 2) value must be measurable, 3) exchange must explicitly exist, 4) knowledge is indispensable, 5) interdisciplinary marketing is inevitable and 6) change is the only marketing constant. it is strongly argued in this research by (Kortam, 2017) that there could be three alternative ways (but not mutually exclusive) to deal with the above designated marketing boundaries in a way that furnish the rationale and mechanism for the proposed universal of non-linear marketing through reconciling and combining contextual marketing knowledge and holistic marketing solutions:-

1- Complying with those marketing boundaries leading to what might be referred to as mainstream marketing research and practices so as to learn more lines of conventional wisdoms about the essence and form of contextual marketing knowledge and holistic marketing solutions.

2- Revisiting those marketing boundaries leading to what might be referred to as critical marketing research and practice so as to unlearn conventional wisdoms about the essence and form of contextual marketing knowledge and holistic marketing solutions.

3- Blurring those marketing boundaries leading to what might be referred to as explosive marketing research and practice, so as to relearn unconventional wisdoms about contextual marketing knowledge and holistic marketing solutions.

(Oskooe, 2011) has cited the reasons for non-linearity can be summarized as follows: structural changes, high amplitude shocks, technological innovation, changes in regulations, characteristics of market microstructure, unreliable and unqualified information, this study has achieved an objective ; verify whether non-linearity exists in stock markets as stipulated by Antoniou et al. (1997) that, due to some reasons such as market microstructure, transaction cost, etc. stock prices are non-linear in nature. The author adopted three different methodologies which had the ability to capture structural breaks and non-linearity in the DGP 
of stock price series (Abakah et al., 2018). Adapting this paper's view of non-linear random phenomena and variables to the universe of marketing, the cross country transcendence and analogies argue for the opinion that the data collected on one market such as Egypt could have acceptable universal generalizations if a suitable analytical data collection design and statistical technique is used such as meta-analysis forest plots and meta-regression. As will be explained in the methodology chapter such approach should help to see the winder non-linear forest of marketing rather the single linear tree of marketing myopia constraints by linear context such as geography and social-culture norms and rituals.

(Groves et al., 2007) presented a study which comes about of an empirical analysis of the relationship between managerial thinking style and ethical decision-making, the Data collected from 200 managers over different organizations and industries demonstrated that managers transcendently adopt a utilitarian perspective when forming ethical expectation over a series of business ethics vignettes, managers utilizing a balanced linear/nonlinear thinking illustrated a greater overall eagerness to provide ethical decisions across ethics vignettes compared to managers with a predominantly linear thinking style. The contribution of this study appeared unexpectedly that managers utilizing a balanced linear/nonlinear considering style were slightest likely to receive an act utilitarian rationale for ethical decision-making over the vignettes, recommending that balanced thinkers may be more likely to create ethical decisions by considering a more extensive extend of alternatives and administering out those that are justified exclusively on the premise of their results (Groves et al., 2007).

Granger (1989) also argues that univariate and multivariate non-linear models express the suitable way to model a real world that is "almost certainly non-linear". Linear and non-linear Granger Causality tests are utilized in arrange to examine the dynamic relationship between stock returns of six Asian Stock Markets, specifically Japan, Hong Kong, Singapore, Malaysia, Taiwan and Thailand, for the time, sometime recently, during and after the stock market crisis of October 1997. The intrigued of this paper is centered on how the crisis was spread between these economies, which are among the strongest of the Asian block. The outcomes present the presence of a bi-directional non-linear Granger causality between the Asian stock markets within the whole period of study, that's from January 2, 1997 to October 1, 1998 (Alexakis, 1999).

A more predictive paper of non-linear causality modeling was made by (Domegan et al., 2017) who has made a wide comparison over the past years between linear and non-linear causality in defining and solving the problems; the main differences is that linear causality is the foremost prevalent premise for problem identification and definition in social marketing, continuous concomitant variation, temporal and non-spurious association struggles are highlighted by Hastings et al. (2005), (Domegan et al., 2017) have mentioned that however, not all 'problems' are created equally. In particular, Jonassen $(2000,2003)$ has proposed that problems vary in at least four ways: (1) structured-ness, (2) complexity, (3) dynamicity, and (4) domain specificity or abstractness. First, well-structured problems is characterized by presenting all elements of the problem to the would-be solver; requiring the application of a limited set of rules and principles that are organized in prescriptive ways; and having 
knowable, comprehensible solutions (Jonassen, 2000, 2003). According to (Hisschemöller \& Gupta, 1999), a structured problem or a well-defined problem is to be solved by quantitative techniques and procedures (standard). These types of problems faced by many organizations have similarly characterized problems as having known solutions that can be implemented through the organization's current structures and processes (Heifetz et al., 2009). On the other hand, ill-structured problems have been depicted as possessing problem components that are not well known; holding either numerous solutions or no solutions at all; owning numerous evaluative criteria; and regularly requiring would-be solvers to reveal individual suppositions or beliefs around the problem (Jonassen, 2000, 2003). The boundaries of this sort of problem are diffuse (Hisschemöller \& Gupta, 1999). As (Taleb, 2005) noted that "in the real world one has to guess the problem more than the solution". Second, Problem complexity has been explained as largely concerned with "how many, how clearly, and how reliably components are represented implicitly or explicitly in the problem. The most complex problems are (not systematic) dynamic, that is, its factors change over time" (Jonassen, 2000, p. 68). Dynamicity with complex problems has been explained as a consequence of the fact that the task environment and its factors change over time. Which that means; the conditions of a problem change, the solver must continuously adapt according to the problem" (Jonassen, 2003). Finally, while problems have been detailed to vary in terms of their structured-ness, complexity, and dynamicity, (Jonassen, 2000, 2003) has argued that all problems moreover change in terms of domain and context along an abstract-situated continuum. Particularly, problem-solving activities are arranged, embedded, and thus subordinate on the nature of the context or domain (Jonassen, 2000). ill-structured problems are not always used synonymously (Raisio, 2009) is wicked problems defined as class of social system problems which are ill-formulated, while the information is confusing and there are many customers and decision-makers with conflicting values, and where the ramifications in the whole system are confusing (Churchman, 1967). By definition, the character of wicked problems abandons linear causality and its one single sort of accomplishing behavioral modify outcomes (Rittel \& Webber, 1973). Instead, wicked problems call for the second notion of causality, that is a non-linear causal approach (Domegan et al., 2017). Non-linear causality permits for messy concomitant variation, temporal sequencing; hypothetical support, non-spurious association and interactions among factors. It is important, as pointed out by Weaver (1948) in a defining science and complexity paper, for problems which involve dealing simultaneously with a sizable number of factors which are interrelated into an organic whole, that is wicked, commons and sustainability problems. Non-linearity meets emergent, intelligent, collective, complex, energetic and organized behaviors. It looks for to understand and examine the social interaction pathways and forms between actors who impact one another in reaction to the impact they receive (Macy \& Willer, 2002). It is non-linear causality, not linear causal clarifications, that lends itself to unwinding wicked problems and social alter in social marketing (Domegan et al., 2017).

Whether investigating ants, sparrows, markets, societies or wicked issues, Einstein said that if he had one hour, he would spend 55 minutes defining the problem and 5 minutes to solve it (Domegan et al., 2017). An example of investigating non-linear causal modeling, the ideas of causality and how (Domegan et al., 2017) characterize and outline "wicked" issues as 
problems has critical implications for social marketing research and practice; Linear causality, based on a deductive cause and impact with control of time and the environment framework does not permit for interactions. Interactions are at the heart of wicked problems. Not capturing interdependence over and between macro and micro levels; between behavioral and social alter; over time and in context makes linear research constrained for wicked problems. Non-linear causal displaying, utilized broadly within the mathematical sciences and expanding within the social sciences, offers a way forward for social marketers. Adopting a scientific see of the world where we make information and understanding of wicked problems through a non-linear causal prism opens a collaborative research door to systems and complexity modeling and mapping methods and technologies. (Domegan et al., 2017). In conclusion (Domegan et al., 2017; Kothiyal \& Murthy, 2014) made three transformational contributions to the social marketing paradigm first, as far as contemporary social marketing theory is concerned, (Domegan et al., 2017) provide a methodological perspective in wicked problems that takes the multi facedness of non-linear causality into consideration. They argue that a transition towards non-linear causality takes into consideration reasoned understandings of the complexity, patterns and interlocking dimensions of wicked problems. second, (Domegan et al., 2017) contributed to advancing causal modeling techniques of social marketing models through adopting fuzzy, collective and interpretative tools to bridge the gap between linear and non-linear causality in marketing research on wicked problems. Third, (Domegan, 2017) critically discussed the consequences of adopting non-linear causal reasoning, concerns and limitations of causal modeling focusing on collective intelligence, fuzzy cognitive mapping and system dynamic modeling.

\subsection{Marketing Research Panels / An Empirical Context}

Definitions of longitudinal research are uncommon. A definition by Taris (2000), who described that longitudinal, is data are collected for the same set of research units which might differ from the sampling units /respondents for two or more occasions, allowing for intra-individual comparison across time. While another discussion of longitudinal research related to work and aging phenomena, Ployhart and Vandenberg (2010) defined longitudinal research as research emphasizing the study of change and containing at minimum three repeated observations on at least one of the substantive constructs of interest. (wang et al., 2017) have summarized that, the dialog of time and longitudinal designs has advanced from explicating conceptual and methodological issues included within the evaluation of changes over time (e.g., McGrath \& Rotchford, 1983) to the development and application of data analysis techniques (e.g., Chan, 1998; Chan \& Schmitt, 2000; DeShon, 2012; Liu, Mo, Song, \& Wang, 2016; Wang \& Bodner, 2007; Wang \& Chan, 2011; Wang, Zhou, \& Zhang, 2016), theory rendering (e.g., Ancona et al., 2001; Mitchell \& James, 2001; Vancouver, Tamanini, \& Yoder, 2010; Wang et al., 2016), and methodological decisions in conducting longitudinal studies (e.g., Beal, 2015; Bolger, Davis, \& Rafaeli, 2003; Ployhart \& Vandenberg, 2010). (Vocino et al, 2015) Panel members are selected through various forums and are welcomed to connect an online panel, where they concur to get invitations to take part in research (Couper, 2000). As part of the registration process, panel members are inquired to complete a profile survey that portrays their demographic characteristics as well as a few behavioral 
characteristics (Callegaro \& DiSogra, 2008).

The consumer panel group usually could be a good cross-section of the population. They may be inquire to keep a diary, answer questions online, or attend a focus group meeting. There may be a visit to their actual homes for research of buying habits and propensities. These panels run over a few period of time, surveys and focus groups is different. The focus group involves some degree of opinion and emotional descriptions, while the questionnaire is just a matter of replying pre-formed questions. A focus group will have a facilitator to coordinate the questioning and take a record of answers and can be done without personally interacting with the group members. In any case, this is a more expensive method so, it is used to collect complex information and studies. The common consumer marketing research focuses on buying habits of consumers, while business research focuses on products sold in the business-to-business field. Research can explore behavioral components that influence buying decisions, or emotions, or other subjective factors. To do this research, it is essential to gather facts and opinions in an objective manner, in an orderly process. The objective is to drag out from the panel what individuals need to buy, more than just how they feel about a particular product. Once the needs are discovered, they can be incorporated into products.

A marketing research panel study may be requested by the manufacturer of an product or by a retail organization attempting to determine what products to add to their stock list. Usually management or marketing departments are the ingrain of such research. They may devise their own groups, or call upon marketing research experts who specialize in this sort of research. Research involves collecting information, analysis, and interpreting data for the customer. First, it is important to define a problem / opportunity, or the reason of this study. Then it is necessary to determine what information is needed to gain in order to work with the problem / opportunity for improvement. After the panel answers, those findings must be interpreted, implications made, and the researchers present a set of recommendations to fix the problem or seize opportunities to the product to better meet consumer demand.

Business market research panels are more particularly situated towards business. There could be more discussion or questions about competition, government legislation, the economy, the market and other factors that are related to that sort of business. The business panels may be more specialized toward particular markets. Some firms have these specialized market research panels available regularly, rather than making them from scratch every time they are needed, and they may have many numerous types of specialized panels accessible to the business community.

Market research agencies like Research and Marketing Strategies, Inc. (RMS) partner with the clients for creating company-specific panels, (George, 2011) mentioned that there is huge differences between a general consumer panel and a client panel; The first is a pool of general participants where specific ties to a company are not essential while the other is a pool of specific participants who have some level of a relationship and history with a company. Thus, client panels do not have to be customers of your company, but they have some intrigued in your company's business or your industry. Also getting client panels is a popular trend in the marketing research industry and is an emerging trend with many of more regional and 
worldwide clients offering an endless amount of benefits for researchers; Here are four quick evident insights into using client panels in marketing research for its evolutionary phases (George K, 2011) ;-

1- Customers become stakeholders: when the client inquired to opt-in for a panel they are choosing to voice their suppositions on the product or services. It is nearly as if they feel like they are taking proprietorship of making the business superior for themselves and others. A few respondents feel like common survey responses may never be seen by somebody within the company who can make a distinction. At least with a panel, they feel as in spite of the fact that their voice is being listened.

2- Continual top-of-mind interest through engagement: by picking into the panel, participants are opening themselves up to get welcomes to take part in your company's future research. It is fair another opportunity to keep your business within the forefront of the customer's intellect and in their minds. Other than the time it takes to manage the panel, paying panel participants point or dollar-based motivations and it is essentially free advertising.

3- Quick and constructive feedback on topics: Having a comprehensive panel may be a speedy way to induce a brief survey to your target audience and collect feedback immediately on quick questions like: - Did you just run a new radio advertisement or send out a direct mailing piece to your whole client base? Do you wish to discover out what clients thought of it?

4- Longitudinal measurement of attitudes, perceptions, and behaviors: If the company has a large enough panel, this panel will provide the company with the opportunity to track a number of metrics over time. For instance, the company can create a benchmark metric of perceptions of the business, run an advertising campaign, and see how the campaign influenced past perceptions. It also gives the researcher chance to study behavior over a period of time as in what sources are the customers using to gather information about a company? Is usage of one referral website growing while others are declining? All of those findings will help redirect and focus the company's' efforts.

Thus, there are four argued and exploratory evidence that substantiate the methodological values of using client panels for evolutionary marketing research purposes:

1- Customers become stakeholders, allowing and viewing customers to become stakeholders imply that marketing research can easily create a greater variation according to highly different customer's profile, needs, buying processes and customer values. Since the customer is examined as a stakeholder a much greater variation is generated to respondent proactively to the highly distinctive marketing segments.

2- Longitudinal measurement of attitudes, perceptions, and behaviors, the longitude that a collection design as a methodological must to rely on panels create a much wider room for highly rigors selection and grantee creative replication. This takes place through repetitive measured of attitude, perception and behavior on marketing variables and phenomena repetitively using the same measurements tools on the same sample unit over 
argued time intervals.

$>$ According to these two postulates; the comprehensive nature of the encoding phase should be expected to allow for a wide variation of marketing ideas and dimensions to emerge, thus creating a large pool of marketing potential and horizons. This is should lead to the recognition of the highly stochastic nature and essence of most marketing phenomena against any straight line. Therefore, safeguarding the marketing phenomenon against any straight line bias or Conventional stereo typical thinking.

3- Continual top-of-mind interest through engagement, the effective use of marketing research panels keep the focus of customers and other respondents minds on providing data to understand the marketing phenomena under research. This can only happen provided that very systematic and logical research procedures have been followed of previous phases like sampling and measurements to ensure the validity and reliability of scientific method application at this critical selection point.

According to the previous postulate, the application of scientific research methods to reach scientific marketing Solutions should result in a selection of the fittest of the large pool of marketing ideas created by the encoding phase "survival of the fittest". This implies that a marketing insight is asset of interrelated conceptual configuration and empirical test that links several points of comparison. Thus these link ages keep marketing insights away from the superficial description of being on one point only leading to unsafe generalization about the justification of the levels and extensions of marketing variables.

4- Quick and constructive feedback on topics, the adoption of marketing research panels necessaries establishing significant control point all along the marketing research process with a special emphasis on sampling measurement, data preparation and analysis. These control points are sometimes used to replicate some reversible limitation, but their main value lies in guiding the future replication on the research process. A major advantage of this guided replication process is it is time sensitivity, thus the quick feedback triggers a pace of variation that can even precede the pace of market change created by the very fast change of customer mind to coop with ever shorter and shorter product life cycle.

$>$ According to the previous postulate, the application of scientific research methods to reach scientific marketing Solutions should result in a selection of the fittest of the large pool of marketing ideas created by the encoding phase "survival of the fittest". This implies that a marketing insight is asset of interrelated conceptual configuration and empirical test that links several points of comparison. Thus these link ages keep marketing insights away from the superficial description of being on one point only leading to unsafe generalization about the justification of the levels and extensions of marketing variables.

It is quite challenging to find an empirical marketing research institutional platform and applied context to test this multi-faceted research propositions. Panels are argued to be a very comprehensive, regular and relevant testing ground for the arguments made by the 
subsequent proposed conceptual framework. The representativeness of the profile and size of a panel guarantees a minimum level of variation of marketing ideas generated by the diversity of the members of these panels. The common substantial size of the panels that the evident dispersion or variation of the perception and altitude of its sampling units that will cater for rigors application of scientific marketing research method and subsequent objective selection of the fittest of marketing ideas. The relevance of panels to most commonly examined marketing phenomena and variables and the long term commitment of its sampling units to data collection should allow for more effective replications as a consequence of the decoding phase.

\section{Exploratory Evidence}

A part from the Literature Review two main research activities have been undertaken to support the formulation of research problem and hypothesis as follows:

\subsection{Analysis of Secondary Data}

A longitudinal study or panel study is a quasi-experimental research plan that includes repeated observations of the same variables over long periods of time, frequently many decades. It is regularly a type of observational study, although they can too be structured as longitudinal randomized experiments (William, 2002).

(Wang et al., 2017) An imperative meta-trend in work, aging, and retirement research is the increased appreciation of the worldly nature of the phenomena under investigation and the imperative part that longitudinal study designs play in understanding them (e.g., Heybroek, Haynes, \& Baxter, 2015; Madero-Cabib, Gauthier, \& Le Goff, 2016; Wang, 2007; Warren, 2015; Weikamp \& Göritz, 2015).

The following table (1) expresses the most studies (Panels) with high impact, participants and remarks:-

\begin{tabular}{|c|c|c|c|c|c|}
\hline Study name & Reference & $\begin{array}{c}\text { Country or } \\
\text { region }\end{array}$ & $\begin{array}{c}\text { Year } \\
\text { started }\end{array}$ & participants & Remarks \\
\hline $\begin{array}{l}\frac{\text { Colombian }}{\text { Longitudinal }} \\
\frac{\text { (Universidad de }}{\text { los Andes) }}\end{array}$ & (ELCA,2013) & Colombia & 2010 & 15,363 & $\begin{array}{l}\text { Follows rural and urban households } \\
\text { for increasing the comprehension of } \\
\text { social and economic changes in } \\
\text { Colombia. }\end{array}$ \\
\hline$\frac{\underline{\text { British }}}{\text { Household Panel }}$ & PFID,2013 & $\begin{array}{l}\text { United } \\
\text { Kingdom }\end{array}$ & 1991 & $\begin{array}{c}75,000 \\
\text { individuals, } \\
\text { spanning as } \\
\text { many as } 4 \\
\text { decades of } \\
\text { their lives }\end{array}$ & $\begin{array}{l}\text { - Information is collected about all } \\
\text { individuals in the family; the greatest } \\
\text { level of detail is ascertained for the } \\
\text { primary adult(s) heading the family. }\end{array}$ \\
\hline $\begin{array}{l}\text { Busselton Health } \\
\text { Study }\end{array}$ & BPMR,2016 & Australia & 1966 & 10,000 & $\begin{array}{l}\text { - Effects and characteristics of diabetes } \\
\text { in a semi-rural population and is }\end{array}$ \\
\hline
\end{tabular}




\begin{tabular}{|c|c|c|c|c|c|}
\hline & & & & & $\begin{array}{l}\text { based on the long running Fremantle } \\
\text { Diabetes Studies. }\end{array}$ \\
\hline$\frac{\text { Socio-Economic }}{\underline{\text { Panel }(\text { SOEP) }}}$ & SOEP,2016) & Germany & 1984 & 12,000 & $\begin{array}{l}\text { - a longitudinal panel dataset of the } \\
\text { population in Germany ,include } \\
\text { household composition, occupation, } \\
\text { employment, earnings, health and life } \\
\text { satisfaction. }\end{array}$ \\
\hline $\begin{array}{l}\frac{\text { Household, }}{\text { Income and }} \\
\underline{\text { Labour }} \\
\text { Dynamics in } \\
\text { Australia Survey }\end{array}$ & HILDA,2016 & Australia & 2001 & 25,000 & $\begin{array}{l}\text { Examining issues such as the } \\
\text { incidence of persistent poverty; assets } \\
\text { and income in the transition to } \\
\text { retirement. } \\
\text { - The correlates and impact of changes } \\
\text { in physical and mental health; and an } \\
\text { international comparison of wealth } \\
\text { and happiness. }\end{array}$ \\
\hline $\begin{array}{c}\text { Panel Study of } \\
\text { Belgian } \\
\text { Households }\end{array}$ & (PSHB, 2001) & Belgium & 1992 & 11,000 & $\begin{array}{l}\text { - Information on the nature, frequency } \\
\text { and sequencing of the changes that } \\
\text { modify the ways of living } \\
\text { - Also to evaluate their influence on } \\
\text { the moral and material well-being of } \\
\text { the Belgian population. }\end{array}$ \\
\hline$\frac{\text { Panel Study of }}{\underline{\text { Income }}} \underset{\underline{\text { Dynamics }}}{ }$ & (PSID,2016) & $\begin{array}{l}\text { United } \\
\text { States }\end{array}$ & 1968 & 70,000 & $\begin{array}{l}\text { - Possibly the oldest household } \\
\text { longitudinal survey in the US. } \\
\text { - measures economic, social, and } \\
\text { health factors over the life course of } \\
\text { families over multiple generations }\end{array}$ \\
\hline $\begin{array}{l}\frac{\text { Understanding }}{\text { Society: The UK }} \\
\underline{\text { Household }} \\
\frac{\text { Longitudinal }}{\text { Study }}\end{array}$ & $\begin{array}{l}\text { UKHLS, } \\
2016\end{array}$ & $\begin{array}{l}\text { United } \\
\text { Kingdom }\end{array}$ & 2009 & $\begin{array}{c}40,000 \\
\text { households or } \\
\text { approximately } \\
100,000 \\
\text { individuals. }\end{array}$ & $\begin{array}{l}\text { - It is the largest panel survey in the } \\
\text { world supporting social and } \\
\text { economic research. } \\
\text { Measure phenomena such as } \\
\text { poverty, persistence, unemployment } \\
\text { duration, duration of marriage or } \\
\text { cohabitation. } \\
\text { analyze the factors that affect these } \\
\text { durations }\end{array}$ \\
\hline $\begin{array}{c}\text { ONS } \\
\text { Longitudinal } \\
\text { Study }\end{array}$ & ONS,2016 & $\begin{array}{l}\text { England } \\
\text { and Wales }\end{array}$ & $\begin{array}{l}1974 \\
\text { (data } \\
\text { from } \\
1971)\end{array}$ & $\begin{array}{l}1 \% \text { sample of } \\
\text { the population } \\
\text { of England } \\
\text { and Wales. } \\
\text { The LS } \\
\text { contains } \\
\text { records on } \\
\text { over 500,000 }\end{array}$ & $\begin{array}{l}\text { - It is largely representative of the } \\
\text { whole population in England and } \\
\text { Wales. } \\
\text { - In addition to the census records, the } \\
\text { individual LS records contain data for } \\
\text { events such as deaths, births to } \\
\text { sample mothers, emigrations and } \\
\text { cancer registrations. }\end{array}$ \\
\hline
\end{tabular}




\begin{tabular}{|c|c|c|c|c|c|}
\hline & & & & $\begin{array}{c}\text { people. } 1 \\
\text { million } \\
\text { sample } \\
\text { members has } \\
\text { been collected } \\
\text { over the } 40 \\
\text { years of the } \\
\text { study }\end{array}$ & $\begin{array}{l}\text { - Census information is also included } \\
\text { for all people living in the same } \\
\text { household as the LS member. } \\
\text { - The ability to combine detailed } \\
\text { personal characteristics with area } \\
\text { characteristics has proved useful in } \\
\text { many studies of health. } \\
\text { - Link social, occupational and } \\
\text { demographic information to data on } \\
\text { life events. Examples include studies } \\
\text { of mortality, cancer incidence and } \\
\text { survival, and fertility patterns. }\end{array}$ \\
\hline $\begin{array}{c}\text { Scottish } \\
\text { Longitudinal } \\
\text { Study } \\
\text { Development and } \\
\text { support unit } \\
\text { (SLS-DSU) }\end{array}$ & $\begin{array}{c}\text { (SLS-DSU,2 } \\
016)\end{array}$ & Scotland & 1991 & $\begin{array}{l}5.3 \% \text { sample } \\
\text { population of } \\
\text { the Scottish } \\
\text { carry records } \\
\text { on almost } \\
274,000 \\
\text { individuals } \\
\text { using } 20 \\
\text { random } \\
\text { birthdates. }\end{array}$ & $\begin{array}{l}\text { - The SLS is a large-scale linkage } \\
\text { study built upon census records from } \\
1991 \text { onwards, with links to } \\
\text { necessary events (births, deaths, } \\
\text { marriages, emigration). } \\
\text { Ecological and geographical } \\
\text { information (deprivation indices, } \\
\text { pollution, weather); primary and } \\
\text { secondary education data (attendance, } \\
\text { Schools Census, qualifications) } \\
\text { Cancer registrations, maternity } \\
\text { records, hospital admissions, } \\
\text { prescribing data and mental health } \\
\text { admissions. } \\
\text { The research potential is } \\
\text { considerable. The SLS is a replica of } \\
\text { the ONS Longitudinal Study but with } \\
\text { some key differences: sample size, } \\
\text { commencement point and the } \\
\text { inclusion of specific variables. }\end{array}$ \\
\hline $\begin{array}{c}\text { Northern Ireland } \\
\text { Longitudinal } \\
\text { Study } \\
\text { (NILS-RSU) }\end{array}$ & $\begin{array}{c}\text { (NILS-RSU,2 } \\
016)\end{array}$ & $\begin{array}{l}\text { Northern } \\
\text { Ireland }\end{array}$ & 2006 & $\begin{array}{l}28 \% \text { of the } \\
\text { Northern } \\
\text { Ireland } \\
\text { population } \\
\text { (almost } \\
500,000 \\
\text { individuals } \\
\text { and } \\
\text { approximately }\end{array}$ & $\begin{array}{l}\text { The NILS is a large-scale, } \\
\text { representative data-linkage study } \\
\text { made by linking data from the } \\
\text { Northern Ireland Health Card } \\
\text { Registration system to the 1981, } \\
1991,2001 \text { and } 2011 \text { census returns } \\
\text { and to administrative data from other } \\
\text { sources. } \\
\text { - These include necessary events }\end{array}$ \\
\hline
\end{tabular}




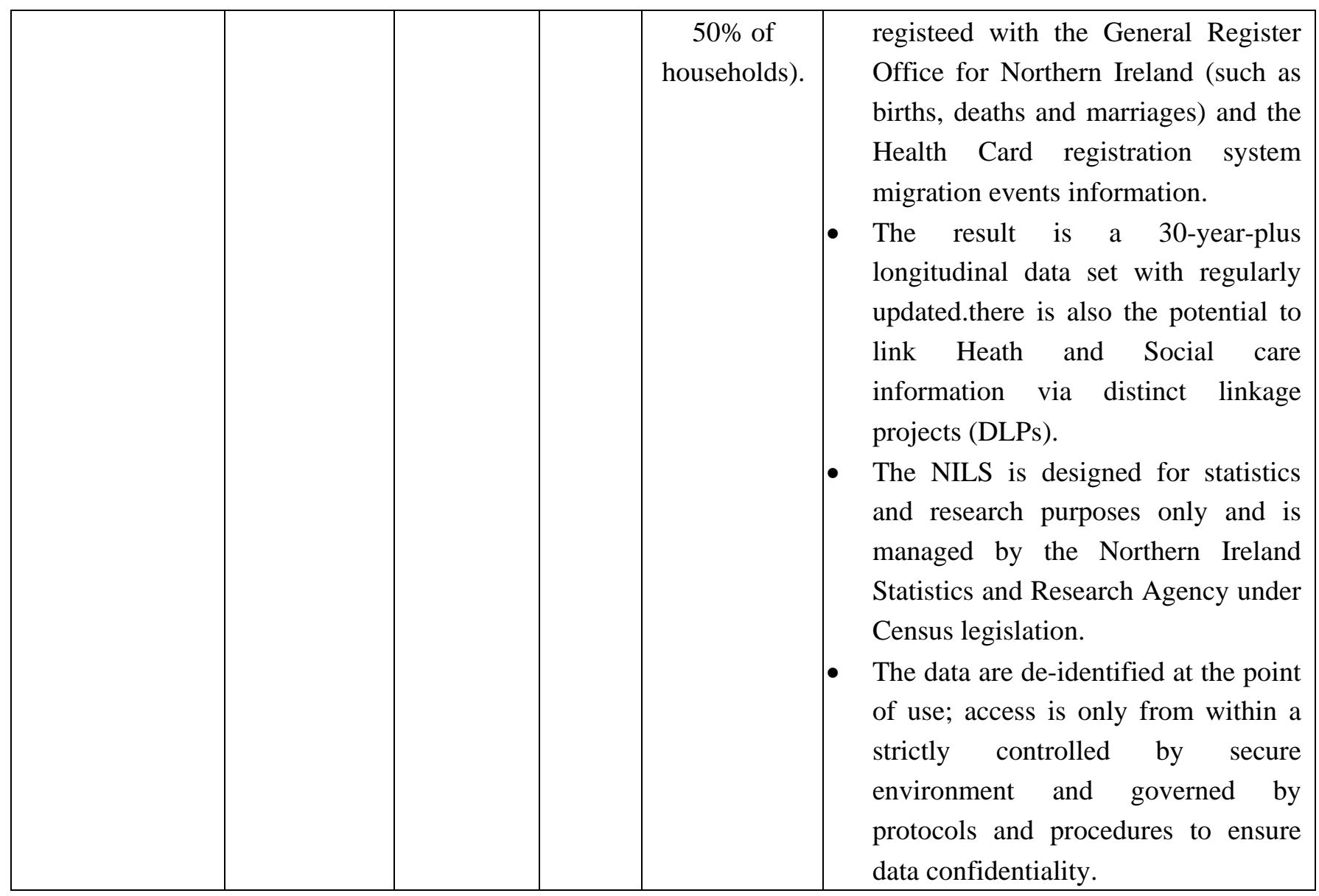

\subsection{Qualitative Research with Concerned Parties}

In order to obtain and in-depth understanding of the rationale and sought benefits of consumer panels a focus group was conducted with five marketing research managers at A.C Nielsen over a period of three hours. The following issues were raised according to the adopting focus group guides; Main uses of consumer panels in marketing research projects, kinds of measurement scales adopted for panels, Venus for analysis of panels output data and how data collect from panels is replicated also, The following main conclusions were obtained from the focus groups:-

1) Panels are mainly used for measurements of five specific marketing phenomena namely; - 1- customer satisfaction 2- customer value 3- brand image 4- new product feasibility 5advertising effectiveness. These research purposes are used a cross a specific number of contexts mainly in the areas of shopping malls, banks, hotels, automobile service centers and fast food restaurants.

2) The main measurement scales developed for collecting data from panels are interval scales for demographics; the same scales are used over and over again without making any changes except for necessary context-specific features.

3) The panels though theoretically considered essential for longitudinal designs, focus 
group members asserted clearly they are much more commonly used for one-single and multiple cross sectional designs. It was also explicitly stated by marketing research managers that the scales are never adopted and/or changed from time to time in longitudinal studies or a cross markets in cross-sectional designs. They stressed that these scales represent the know-how based brand of the agency.

4) The output data of panels are usually analyzed using highly standardized data analysis techniques. While chi-squared is the main non-parametric statistical technique for demographic data, mean and standard deviation are the mainly adopted the descriptive statistical tools. The main parametric statistical techniques use for inferential purposes are mainly the T-test, $\mathrm{F}$ test and Z-test. These techniques are almost fixed for all kinds of panel-based marketing research applications. Multi varied data analysis techniques are very rarely used with exclusive emphasis multiple regressions.

5) As above indicated the whole marketing research process starting from panel selection going through deciding on research objectives, measurements scales and data analysis techniques are automatically replicated with very few changes mainly trigged by clients demands.

\section{Research Gap / Linking the Detached Jigsaw of Evolutionary Marketing Research}

The main motivation for carrying out this multi frames interdisciplinary research is the critical need to change the essence, philosophy and patterns of marketing research as an inevitable adaptable marketing ideology and methodology for achieving the increasingly higher academic and professional marketing agenda in theory and practice. This motivation can be expressed in one comprehensive research gap that is composed of four consecutive intellectual episodes first, the prime concern of the researcher as a marketing research academic (and advisor) is to make the principles, process and consequences of marketing research much more evolutionary i.e phased, logical, value driven and time sensitive. As postulated marketing research is means to end and those ends are manifested in improving the capacity to safely generalize on the description, explanation, prediction and manipulation of marketing phenomena and variables. This research advocated the dominant view that marketing phenomena and variables are becoming increasingly phased, step-wise, time-based and non-linear. Second, subsequently investigating such kinds of marketing phenomena and variables can only be achieved through a similarly dynamic ever evolving and precisely guided marketing research. The proposed stages theory of encoding-application and decoding theory of marketing research served to provide a more insightful view-from-a-bridge on the marketing research process. Yet, it has fallen short of injecting a research theorization of a true evolutionary philosophy and essence of the marketing research process. A universal dynamic and inspiring interdisciplinary framework such as generalized Darwinism introducing the vigorous and rigors time driven evolution of variation, selection and replication furnished the conceptual space for evolution marketing research theory to flourish with much deeper and broader universal substance. This research proposal initially that substances can be attend through the triangulation of variation as a drive for encoding, selection as a drive for replication and implication as a drive for decoding. The controversial 
positive contribution of this integration between generalized Darwinism and evolutionary marketing research needs the careful selection of a strong-grounded and collectively needed theoretical platform to reflect its much desirable consequences. Third, consequently non-linear marketing and its sought agenda to improve the academic and practical abilities to handed marketing phenomena make marketing insights and forecast marketing outlooks where carefully adopted as a platform mirror to reflect the theoretical intelligentsia of a generalized Darwinism theory of marketing research. The fourth episode was the challenge to come up with an empirical appropriate context that can substantiate the dimension of generalized Darwinism as link to evolutionary marketing research with a view toward fulfilling non-linear marketing contributions. This research surprisingly argue that only one empirical context that truly and faithfully gives room to the step-wise, time based, logical and non-linear flow of using marketing research to solve marketing problems/seize marketing opportunities/build and sustain marketing based competitive advantage is marketing research panels used for longitudinal profiling of marketing phenomena and variables.

Conclusively the research gap that need to be bridged by the conceptual framework that will be articulated in details in next chapter that there is a need for further research to base a theory of evolution marketing research on a generalized Darwinism paradigm and reflect the consequences of such synthesis through a non-linear marketing agenda through an empirical refined testing process relying on marketing research panels for longitudinal purposes.

\section{Aim of Research}

This research paper strives to adapt the principles of generalized Darwinism to augment evolutionary marketing research with a view toward achieving the non-linear marketing agenda of: 1- Creating a variation of marketing ideas to support the encoding phase of evolutionary marketing research to improve the nonlinear description of marketing phenomena. 2- Strengthening the rigors selection of varied marketing ideas through supporting the application phase of evolutionary marketing research to develop a multi-point marketing insight of marketing variables.3- Seeking to replicate continually improved variation and selection process to support the decoding phase of evolutionary marketing research to Provides a more accurate outlook of marketing phenomena and variables.

\section{The Proposed Conceptual Model}

The proposed conceptual model for this research aims to bridge the gap as explained above through introducing the testable research hypotheses for empirical refinement of the model. The model like the research gap is grounded on the triangulation among the literature review, analysis of secondary data and exploratory qualitative research along with the researcher's deductive reasoning to take the argument further into advanced frontiers that has the promise and potential to make an original contributions to the theoretical development and policy implications of the subject area of evolutionary marketing research accordingly the following aspects constitute the main billers of the conceptual model:

\subsection{Underling Rationale of the Model}


The reason for argument for a new model of universal need for another elaborate model in marketing research estimates from the over emphases of marketing research as an activity and a function rather than a leading philosophy for marketing thinking and doing. The literature review and the exploratory evidence clearly indicate that a majority of marketing research scholars and professionals treated as an activity that must be probably conducted against highly technical professional standards while this grantees to a large extent the rigor of marketing research, it also could lead to significant myopia of marketing research, limiting its contributions to very situational boundaries of required client deliverables, time, industry and country which is very evidently the case-fewer studies can be classified as looking at marketing research from a functional perspective, thus integrating it into the wider framework of the landscape of marketing, usually estate as the good old marketing mix. Though the function perspective on marketing research extent its value to problem-solving and/or opportunity seizing, it is still considerably constraints by the conventional wisdom of its larger framework of marketing as a function where it belongs. Nevertheless the marketing mix paradigm has been significantly revisited, questions and even reimagined (as SIVA for example) no such critical reviews have followed for marketing research as a sequence. Very little research efforts have seriously endeavors to crack the nutshell of marketing research as a professional activity or an information function. The role of marketing research in building and sustaining competitive advantage and as a catalyst of original change needs to look at marketing research as a leading and probably dominant marketing philosophy. The holistic framework of knowledge based marketing promised a great deal in this regard but unfortunately ended up with adopting a technological insight rather than a marketing research driven foresight of marketing knowledge, let alone marketing wisdom and truth. This research argues for a critical and argent need for adapting interdisciplinary universes from outside the marketing arena to serve as a liberal platform that release marketing research from its very limiting contemporary assumptions and roles adopting the proposed paradigms of evolutionary marketing research moving through the phases of generalized Darwinism which served quiet effectively and successfully in broaden the scope of many universal theories across a number of social sciences as evidence in the literature review, thus the governing logic in the model is to argue for clear conceptual links where the main principles of Generalized Darwinism could guide the phases of evolutionary marketing research by the driving force of the processes of variation, selection and replication. Another revolutionary reflection of such links can be viewed as the transformational theme of non-linear marketing that also aimed to liberate marketing research among other marketing disciplines for more explosive horizons ( and thus much more useful) postulate for marketing thinking and doing.

\subsection{Objectives of the Model}

The underlying rationale of the model targets the accomplishment of four far reaching objectives:-

1) Making marketing research more evolutionary in a universal way that fits among most marketing contexts.

2) Successful adaptations to achieve in-depth and generalized universal development of an 
evolutionary marketing research theory.

3) Demonstrating the unique and original value-added of generalized-Darwinism-based evolutionary marketing research theory through the new conceptual platform of non-linear marketing contributions.

4) Empirically testing the whole conceptual framework through time sensitive panel, context and longitudinal data.

\subsection{Anticipated Contributions of the Model}

It is expected that the following theory and policy implications would result from formulating the model as new contributions made by this research:-

1) Introducing a clear understanding of how generalized Darwinism can broaden and deepen marketing research concepts and principles to be philosophical enough through being evolutionary insightful and foresightful.

2) Conceptualization of Darwinism based evolutionary marketing research as a devise theory to be highly philosophical adequate to achieve higher marketing ends like marketing research dualities of ideology/ methodology, truth/wisdom, gap between theory and practice and improving marketing as a science intellectually and empirically (intelligentsia /empiricism).

3) Visualization of a tangible achievement of higher marketing ends through optimization of non-linear marketing deliverables.

4) Opening new venues for examining advanced marketing research issues through real innovative and highly un-tested marketing research contexts such as marketing research panels and marketing research analytical techniques such as meta-analysis.

\subsection{Limitation of the Model}

There can be a limitation of each above contribution for making the generalization to make them safe:-

1) Contribution one is limited by the use of Generalized Darwinism as one conceptual interpretation of Darwinism and by Darwinism in its broad sense as one philosophical drive for advanced marketing research which might include relativity, argumentation and critic.

2) Contribution two is limited by using marketing research alone as one critical landmark of the marketing landscape. Further reference could be made to potential evolutionary strategic marketing, buyer behavior and marketing management.

3) Contribution three is limited by the argument that non-linear contributions represent one of at least three more high areas of marketing agenda including polarized and explosive marketing wisdom.

4) contribution four is limited by the use of panels while there is also could be room for systematic sampling and quota sampling as time sensitive and population focused context of 
marketing research. Also, logistic regression, cluster analysis and path analysis could be useful and valid replacements of meta-analysis for the same non-linear or other higher marketing ends.

\subsection{Structure and Main Arguments of the Model and Its Hypotheses}

This model argues for the perspective and view that adopting generalized Darwinism framework should make marketing research more evolutionary and universal. Therefore evolutionary marketing research theory should make a significant optimization of higher marketing ends that is poorly fulfilled so far such as non-linear marketing contributions. Finally, this totally new born marketing philosophy should be expected to work on marketing research panel's data as an empirical context to refine and further developed the proposed integration of Darwinism and marketing research.

It is contended by this research that encoding marketing problems/ opportunities in to scientific terms should expand variation of marketing ideas. The comprehensive and unstructured nature of the encoding stage ought to be expected to permit for a more extensive of marketing ideas and dimensions to develop, hence making a large pool of marketing potentials and horizons. This ought to lead to the acknowledgment of the multidimensional and highly stochastic nature and substance of most marketing phenomena. There for the carve Lanier and arrangement of lines communicating a marketing phenomenon would defend it against any straight line bias or conventional stereotypical thinking and considering.

The application of scientific research methods to reach scientific marketing solutions ought to result in a selection of the fittest of the large pool of marketing ideas made by the encoding phase. The rigor and majestic substantiation of this stage should create exceedingly grounded and entirely screaming process depending on highly scientific standards and guidelines. subsequently ruthless exclusion and inclusion process of marketing ideas will take place for filling the guideline and principle of "survival of the fittest" of those thoughts. This phase and it's highly regulars selection mechanism accentuation the relativity of marketing truth. This reflection infers that a marketing insight is resource of interrelated conceptual configuration and empirical test that links many points of comparison. In this way, these linkages keep marketing insights absent from the superficial description of being on one point only leading to unsafe generalizations about the justifications of the levels and extensions of marketing variables.

Decoding of scientific marketing solutions into actionable marketing decisions and polices ought to deliver room for an progressively quickened and dynamic replication process of variation and selection. The goal important highlights of the decoding phase open more venous for future marketing research that points to create indeed more varieties of marketing ideas at the replicated encoding phase. On the other hand the decoding phase revels more suitable measures standards of selection bringing approximately indeed more regress screening and subsequent survival of only the fittest of the fittest of marketing ideas at the applications phase. These replications inevitably result in more proudly elaborate and sophisticated advanced understandings of the substance of marketing phenomena. Furthermore more depth of marketing insights will materialize as more smart linkages 
between points of signals are found as a result of such replications. Eventually this leads to creating angle expressions of long-term outlook of marketing phenomena that moves away from over streamlined sharp angle extrapolation into more foresight-oriented anticipation of the phenomena.

The pervious exploratory research in terms of secondary data analysis and qualitative research with marketing research managers implies an evident policy / practice gap. This gap lies in the limiting ability of marketing research agencies to provide marketing knowledge that can be an opportunity seizer/ problem solver or a unique source of competitive advantage. The clearly evident stereo typical approach of marketing research agencies to conducting panels based research narrows down the possibility to produce real opportunities for competitive superiority. The limited testing power of used statistical technique for selection limits the possibility of reaching out to those opportunities and problems that truly mattered to the majority of customer base. Consequently the highest standardized methodological over dominates of the marketing research process allows little ever creative and iterative replication of the variation and selection process leading to further deprivation of access to real opportunity, problem and competitive advantage which erode over time. Thus, totally innovation and ideological approaches such as Darwinism and evolutionary marketing research should help should help in providing true adaptation and feedback to the marketing research process. Even though non-linear marketing and panels are only the empirical context and platform for the ideology of this research, in practical terms they can be thought of as real ground for making greater horizons for new venous of marketing based competitiveness in emerging global, multi-dimension and highly dynamic market places.

The conceptual framework can be argued by this research to bridge a critical research gap that cause for moving into a universe of non-linear marketing, bridging this gap should be expected to secure moving away from the limitations and dangers of straight line, one point and sharp angle illusive prejudices of marketing phenomena, insights and outlooks. The adoption of a generalized Darwinism- supported evolutionary marketing research should provide a strong research initiates for a non-linear market agenda to produce a more realistic, in-depth and forward thinking and doing of marketing phenomena, insights and outlooks. Arguably, improve preventions of marketing as a science and catering for a visible bridging of the gap between marketing theory and practice.

The following figure depicts the proposed conceptual model which is followed by the testable hypotheses expressed by the main argument of this research. 


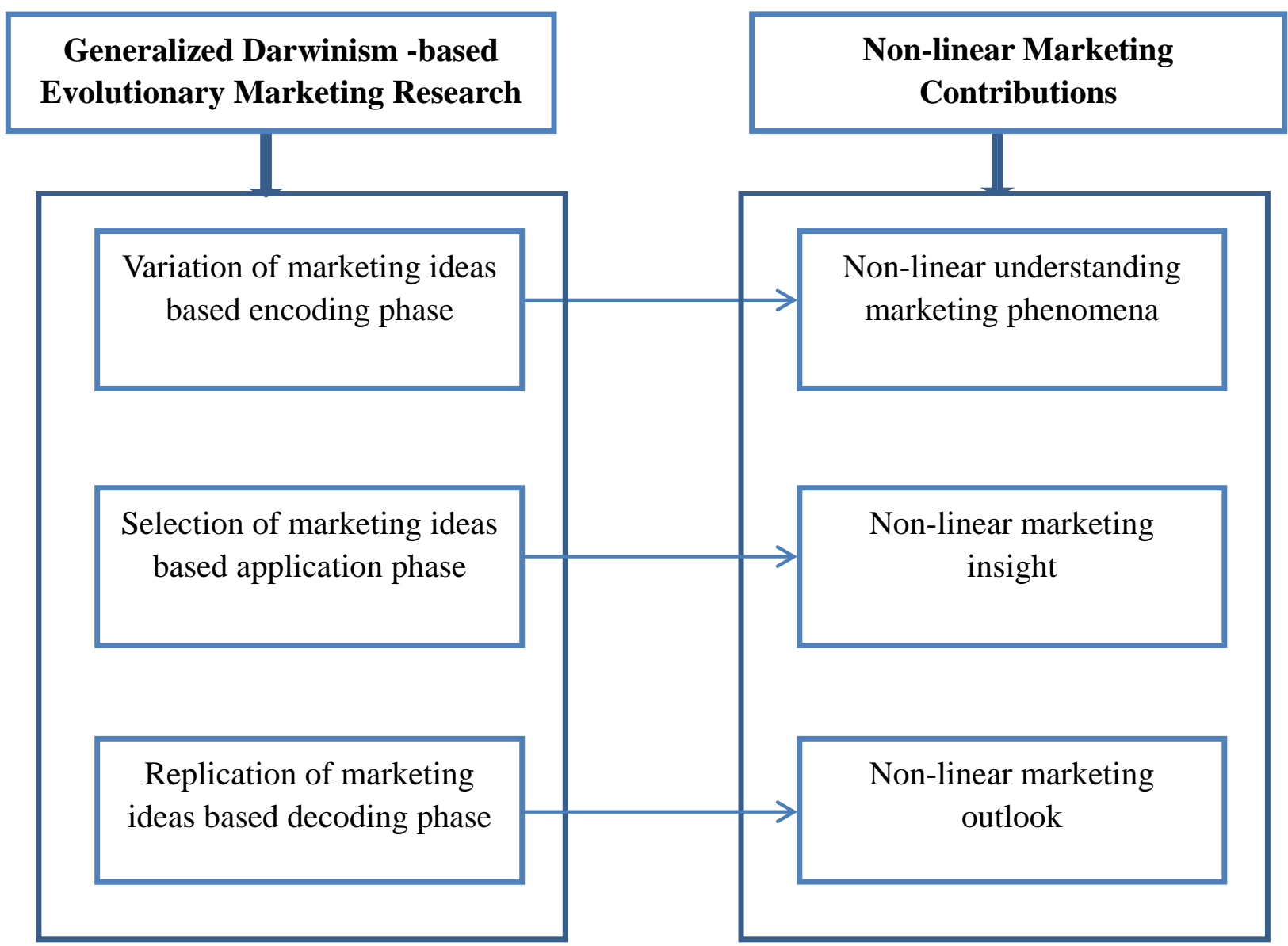

Figure 1. The conceptual model

\section{Conclusive Embark- Research Propositions and Proposed Methodology}

The proposed conceptual framework advocates the following research hypotheses:

R1: variation-based- encoding of marketing ideas has a significant and positive impact on non-linear underlying of marketing phenomena.

R2: selection-based application of marketing methods has a significant and positive impact on non-linear description of marketing insights.

R3: replication-based decoding has a significant and positive impact on non-linear prediction of marketing outlooks.

\section{Planned Research Methodology}

The research methodology that adopted in this research used to investigate the research's hypotheses. The following aspects will be discussed;-

\subsection{Research Design}

Research design is divided into exploratory research design and conclusive causal design:- 
1) Exploratory research to define research gap, design conceptual model and formulate research hypothesis consisting of $\mathrm{A}$. analysis of secondary data on the profiles uses and findings of advanced world-wide applications of marketing research panels. BQualitative research with concerned parties, in-depth interviews with marketing research managers and marketing researchers on the shop floor in the field to explore when panels are needed and how they are used and the customers short comings and draw backs of prevailing marketing research methodologies and ideologies and how they reflect on the ability of marketing research to provide non-linear outside the box marketing solutions to real marketing problems through adopting truly innovative marketing research philosophies and overall mechanisms like generalized Darwinism based evolutionary marketing research theory.

2) Conclusive causal design which aims to detect, measure and analyze the impact of generalized Darwinism based evolutionary marketing research theory on for-filling through non-linear marketing contributions through a probably equipped marketing research create for marketing research to become an effective problem solver, opportunity seizer and competitive advantage builder and sustainer. The meta-analysis will be the main new design for determining the existence and directions of such causal relationships based on forest plots of a sample of panel-based marketing research reports that seek through insightful and representative measurement of causalities among the independent variables which consolidate the three main underlying dimensions of generalized Darwinism of non-linear marketing contributions. Accordingly this research introduces a methodological contribution through blending a cross-sectional design in terms of industries and countries and longitudinal design in terms of time horizons not in a mutually exclusive sense but in a rare case of integration sense.

\subsection{Sampling Design and Plan}

The sampling unit for this research would be all panels based marketing research reports on various industrial / organizations, countries/ cultures and time horizons because according to the literature, exploratory those reports are the valid and reliable carriers and containers of the extent of Darwinism/ evolutionary methodologies and non-linear findings and conclusions since it can never be a matter of absolute qualitative facts, preferences or comparisons or perceptions and attitudes rather it has got to be scientific and professional truths judged by the sophisticates mathematical combinations on the comprehensive level and panoramic essence of meta-analysis originated forest plots (data about the data). According to population are all panel based marketing research reports world-wide conductive by professional recognized marketing research firms, teams and consultancies which by definition is an indefinite population that necessitates the use of sampling guide. the sampling guide was secured through the kind and generous approval of A.C-Nelson Egypt top management to provide a fully-scale of such studies conducted by A.C-Nelson as the market leader and best practice benchmark of their studies across the globe. The sample size was mainly determined by the adequacy for analysis and heterogeneity of population across the sampling dimensions of industry, country and time diversity of marketing research projects. These to sample size 
determination criteria of relative population size and variation of the Darwinism evolutionary phenomena as suggested by the central-limit theorem of longitudinal and cross sectional data. The sampling technique for this research is a genuine cluster sampling of the population away from the conventional wisdom geographical clustering each group of marketing research reports was viewed by the researcher as an internally exhausted and thus ... exclusive cluster of three main categorize of the population in terms of industry classification, country classification and time classification accordingly the sample structure of this research can be expressed as the following portfolio of panel based marketing research reports provided by A.C-Nelson international through its Egypt branch :- Total number of studies $=86$ as the following;

i. Industry level sampling structure 50 manufacturing industries and 36 services.

ii. Region level sampling structure USA and Canada 20 , Europe 20, MENA 20, Latin \& South America 6 and South Europe \& Asia pacific 20.

iii. Time horizon level structure from 1999 to 2000 subtotal (26 study), from 2001 to 2010 with subtotal (30 study) and 2011 to 2019 with subtotal (30 study). Such sub-sample sizes are considered by meta-analysis as adequate and covering all these sampling selection criteria in a representative way.

\subsection{Measurement Scaling and Data Collection}

Ratio scales in the form of a mark of 10 were used to measure all the 9 main variables of this study as expressed by the conceptual model. This was decided as recognition of the essence of variables as quantitative truth measured widely, insightfully and collectively by the unique computation procedures of meta-analysis forest plots. Accordingly 9 ratio scales were developed for the 9 main variables of the model and were fed into the input files of the meta-analysis forest plots as inducted from the marketing research reports by the researcher it can be claimed that those are first time measures to operationalize the newly conceptualize variables of Generalized Darwinism, Evolutionary marketing research and non-linear marketing contributions.

The validity and reliability cannot be tested by the ratio techniques or cronbach alpha and factor analysis since interval, ordinal and multi items scales were not be used, so forest plots have the advantages of providing even more rigorous validity and reliability test through the large number of mathematical combination done to calculate forest plots, thus reflecting the true essence (i.e construct validity and consistency (i.e internal consistency reliability) among the great contextual variation exhibited by the carefully and deliberately selected studies. 


\subsection{Research Variables and Measurement}

Table 2. The Proposed model's variables measurement scales

\begin{tabular}{|c|c|}
\hline Variables & Measurement scales as a mark of ten \\
\hline $\begin{array}{l}\text { 1- Darwinism based- } \\
\text { variation }\end{array}$ & $\begin{array}{l}\text { 1-1- Richness of customer links through information variation. } \\
\text { 1-2- Richness of spotting marketing opportunities and problems } \\
\text { variations. } \\
\text { 1-3- Richness of marketing performance monitors, evaluations and } \\
\text { corrections variations. } \\
\text { 1-4- Richness of marketing decisions and marketing management quality } \\
\text { standards. } \\
\text { 1-5- Richness of marketing understandings across the organization } \\
\text { variations. }\end{array}$ \\
\hline $\begin{array}{l}\text { 2- Darwinism based } \\
\text { selection }\end{array}$ & $\begin{array}{l}\text { 2-1- Rigorous selection of customer links through information. } \\
\text { 2-2- Rigorous selection of marketing opportunities and problems. } \\
\text { 2-3- Rigorous selection of marketing performance monitors, evaluations, } \\
\text { and corrections. } \\
\text { 2-4- Rigorous selection of marketing decisions and management quality } \\
\text { standards. } \\
\text { 2-5- Rigorous selection of marketing understandings across the } \\
\text { organization. }\end{array}$ \\
\hline $\begin{array}{ll}\text { 3- } & \text { Darwinism } \\
& \text { based-replication }\end{array}$ & $\begin{array}{l}\text { 3-1- Future-oriented and relevant replication of customer links through } \\
\text { information. } \\
\text { 3-2- Future-oriented and relevant replication of marketing opportunities } \\
\text { and problems. } \\
\text { 3-3- Future-oriented and relevant replication of marketing performance } \\
\text { monitors, evaluations and corrections. } \\
\text { 3-4- Future-oriented and relevant of marketing decisions and } \\
\text { management standards. } \\
\text { 3-5- Future-oriented and relevant replication of marketing } \\
\text { understandings across the organization. }\end{array}$ \\
\hline $\begin{array}{l}\text { 4- Evolutionary } \\
\text { encoding }\end{array}$ & $\begin{array}{l}\text { 4-1- Insightful and inclusive definition of marketing research gap. } \\
\text { 4-2- Testability of formulated marketing research questions/ hypothesis. }\end{array}$ \\
\hline
\end{tabular}




\begin{tabular}{|c|c|}
\hline $\begin{array}{l}\text { 5- Evolutionary } \\
\text { application }\end{array}$ & $\begin{array}{l}\text { 5-1- Appropriateness of selected marketing research design. } \\
\text { 5-2- Representativeness and magnitudes of sampling design and plans. } \\
\text { 5-3- Validity and reliability of measurement and scaling. } \\
\text { 5-4- Fitness of data preparation. } \\
\text { 5-5- Safe generalization by data analysis. }\end{array}$ \\
\hline $\begin{array}{ll}\text { 6- Evolutionary } \\
\text { decoding }\end{array}$ & $\begin{array}{l}\text { 6-1- Action orientation of data interpretation. } \\
6-2-\text { Foresight of marketing research report preparation and presentation. }\end{array}$ \\
\hline $\begin{array}{l}\text { 7- } \begin{array}{l}\text { Non-linear } \\
\text { phenomenon }\end{array}\end{array}$ & $\begin{array}{l}\text { 7-1- Non-linearity of marketing phenomenon effectiveness. } \\
\text { 7-2- Non-linearity of marketing phenomenon efficiency. } \\
\text { 7-3- Non-linearity of marketing phenomenon adaptability. }\end{array}$ \\
\hline 8- Non-linear insight & $\begin{array}{l}\text { 8-1- Non-linearity of marketing insight effectiveness. } \\
\text { 8-2- Non-linearity of marketing insight efficiency. } \\
\text { 8-3- Non-linearity of marketing insight adaptability. }\end{array}$ \\
\hline 9- Non-linear outlook & $\begin{array}{l}\text { 9-1- Non-linearity of marketing outlook effectiveness. } \\
\text { 9-2- Non-linearity of marketing outlook efficiency. } \\
\text { 9-3- Non-linearity of marketing outlook adaptability. }\end{array}$ \\
\hline
\end{tabular}

Note. Developed by the researcher based on conceptualization of literature, qualitative research and analysis of secondary data.

\subsection{Data Analysis}

Descriptive statistics of the sample data will be unusually presented through the means and standard deviations of forest plots according to the three main division pillars of the sample structure. Validity and reliability tests will be reported for each sample according to the forest plots as above explained in the previous section. Meta-regression will be the main statistical technique for hypothesis testing with special focus on analysis outputs of meta intercepts, meta slopes, meta co-efficient of determination $\mathrm{R}^{2}$, meta residuals and meta $\mathrm{t}$ and $\mathrm{F}$ Significance tests. Though the numerical values of the meta-regression looks on surface like the normal multiple regression ones, they are totally much more different and stronger as they are grounded on the highly routed and connected computations of meta-analysis regression mathematical logic.

\section{References}

Aldrich, H. E. (1999). Organizations Evolving. London: Sage. 
Aldrich, H. E., Hodgson, G. M., Hull, D. L., Knudsen, T., Mokyr, J., \& Vanberg, V. J. (2008). In defence of generalized Darwinism. Journal of Evolutionary Economics, 18(5), 577-596. https://doi.org/10.1007/s00191-008-0110-z.

Andersson, C (2011) Splitting the replicator: Generalized Darwinism and the place of culture in nature. J Econ Behav \& Org., 80, 657-669. https://doi.org/10.1016/j.jebo.2011.06.027

Barnett, W. A. (1996). Commerce, Complexity and Evolution: Topics in Economics, Finance, Marketing and Management. Google Books.

Breslin, D. (2008). A review of the evolutionary approach to the study of entrepreneurship. International Journal of Management Reviews, 10, 399-423. https://doi.org/10.1111/j.1468-2370.2008.00234.x

Breslin, D. (2010). Generalising Darwinism to study socio cultural change. International $\begin{array}{lllll}\text { Journal of Sociology and Social Policy, 30, 427-439. } & \text {. }\end{array}$ https://doi.org/10.1108/01443331011060760.

Breslin, D. (2011). Reviewing a Generalized Darwinist Approach to Studying Socio-Economic Change. Int J Man Rev., 13, 218-235. https://doi.org/10.1111/j.1468-2370.2010.00293.x.

Brittain, J. W., \& Freeman, J. H. (1980). Organizational proliferation and density dependent selection. In J. Kimberley, \& R. Miles (Eds.), The Organizational Life Cycle (pp. 291-338). San Francisco, CA: Jossey-Bass.

Buenstorf, G. (2006). How useful is generalized Darwinism as a framework to study competition and industrial evolution? $J$ Evol Econ., 16(5), 511-527. https://doi.org/10.1007/s00191-006-0035-3

Campbell, D. T. (1960). Blind Variation and Selective Retention in Creative Thought as in other Knowledge Processes. Psych Rev., 63(5), 330-342. http://dx.doi.org/10.1037/h0047553

Campbell, D. T. (1965). Variation, selection and retention in sociocultural evolution. In D. R. Barringer, G. I. Blankstein, \& R. W. Mack (Eds.), Social change in developing areas: A reinterpretation of evolutionary theory (pp. 19-49). Schenkman, Cambridge, MA.

Cherry, K. (2012). What Is Longitudinal Research? Experiments.

Cordes, C. (2006). Darwinism in economics: From analogy to continuity. J Evol Econ., 16(5), 529-541. https://doi.org/10.1007/s00191-006-0027-3

Cordes, C. (2009). The role of biology and culture in Veblenian Consumption Dynamics. JEcon Issues, 43, 115-141. https:// doi/abs/10.2753/JEI0021-3624430106.

Daniels, S., \& Martin, J. (1999). It Is Darwinism - Survival of The Fittest - How Markets and Reputation Shape the Ways in Which Plaintiffs. Lawyers Obtain Clients, Law and Policy, 21(4), 377-399. https://doi.org/10.1111/1467-9930.00078.

Darwin, C. R. (1871). The Descent of Man and Selection in Relation to Sex (1st ed.). London: 
John Murray. https://doi.org/10.1037/12293-000

Dawkins, R. (1976). The Selfish Gene. New York: Oxford University Press.

Dawkins, R. (1983). Universal Darwinism. In D. S. Bendall (Ed.), Evolution from molecules to man (pp. 403-425). Cambridge University Press, Cambridge.

Dennett, D. C. (1994). Darwin's Dangerous Idea. Simon \& Schuster, New York. https://doi.org/10.1086/233714

Drozdenko, R. G., \& Drake, P. D. (2002). Optimal Database Marketing, Sage, Beverly Hills, CA.

Frees, E. (2004). Longitudinal and Panel Data: Analysis and Applications in the Social Sciences. New York: Cambridge University Press. https://doi.org/10.1017/CBO9780511790928

Gunn, B. (1969). Applying Systems Perspective to Marketing Motivation. European Journal of Marketing, 3(1), 18-31. https://doi.org/10.1108/EUM0000000005205

Hannan, M. T., \& Freeman, J. (1977). The population of ecology of organization. American Journal of Sociology, 82, 929-964. https://doi.org/10.1086/226424

Haring, A. (2016). The evolution of marketing research techniques. American marketing association.

Hax, A. C., \& Wilde, D. L. III. (2001). The Delta Project (pp. 63-80). Palgrave, New York, NY. https://doi.org/10.1057/9780230288089_5

Hodgson, G. (2003). The mystery of the routine: The Darwinian destiny of an evolutionary theory or economic change. Revue Economique, 54, 335-384. https://doi.org/10.3917/reco.542.0355.

Hodgson, G. (2005). Generalizing Darwinism to social evolution: Some early attempts. Journal of Economic Issues, 899-914. https://doi.org/10.1080/00213624.2005.11506859.

Hodgson, G. M., \& Knudsen, T. (2006). Dismantling Lamarckism: Why descriptions of socio-economic evolution as Lamarckian are misleading. Journal of Evolutionary Economics, 16, 343-366. https://doi.org/10.1007/s00191-006-0019-3

Hodgson, G. M., \& Knudsen, T. (2006). Why we need a generalized Darwinism: and why a generalized Darwinism is not enough. Journal of Economic Behavior and Organization, 61(1), 1-19. https://doi.org/10.1016/j.jebo.2005.01.004

Hodgson, G. M., \& Knudsen, T. (2010). Darwin's Conjecture: The Search for General Principles of Social and Economic Evolution. Chicago, IL: University of Chicago Press. https://doi.org/10.7208/chicago/9780226346922.001.0001

Hodgson, G., \& Knudsen, T. (2004). The firm as an interactor: firms as vehicles for habits and routines. Journal of Evolutionary Economics, 14, 281-307. https://doi.org/10.1007/s00191-004-0192-1 
Hull, D. L. (1988). Science as a Process. An Evolutionary Account of the Social and Conceptual Development of Science. University of Chicago Press, Chicago and London. https://doi.org/10.1046/j.1420-9101.1990.3030311.x.

Hull, D. L. (1989). The Metaphysics of Evolution. State University of New York Press, Albany.

Jones, S. K. (2006). Creative Strategy in Direct \& Interactive Marketing (3rd ed.). Racom Communications, New York, NY.

Jyh-Shen, C., \& Lee-Yula, P. (2008). The Impact of Social Darwinism Perception, Status Anxiety, Perceived Trust of people and cultural orientation on Customer Ethical Beliefs. Journal of Business Ethics, 7(8), 487-502. https://doi.org/10.1007/s10551-007-9364-x

Kask, J. (2013). On Business Relationships as Darwinism Systems: An Exploration Into How Darwinism Systems Thinking Can Support Business Relationships. Orebro University School of Business, Sweden.

Knudsen, T. (2004). Economic Evolution without Variation, Selection and Retention. Erwägen - Wissen - Ethik, 15, 75-78. http://hdl.handle.net/10419/32647.

Knudsen, T. (2006). Why We Need a Generalized Darwinism and Why Generalized Darwinism is not Enough. Journal of Economic Behavior and Organization, 16(1), 1-19. https://doi.org/10.1016/j.jebo.2005.01.004

Kortam, W. (2010). Adaptability of Marketing Research To Service Industries: The Role of Encoding, Application and Decoding Phases. In K. Wael, \& M. Abeer (Eds.), Insights, Contexts, and Frontiers of Marketing Thought: An Advanced Book.

Kortam, W. (2017). Non-linear marketing: A Universal philosophy of Marketing ThinkingDoing. Perlen: Lambert academic publishing.

Kortam, W., \& Gad, G. (2014). Generalized Darwinism For An Evolution Theory of Marketing Research: Survival For The Fittest of Marketing Knowledge. Proceedings of Marketing Research Summit, Marketing Edge, San Diego, California, USA, October.

Kortam, W., \& Gad, G. (2017). Using Marketing Panels As An Exploratory Empiricism For Substantiation of a Generalized Darwinism-Based Evolutionary Marketing Research. CUCBS,Cairo, Egypt.

Kortam, W., Mahrous, A., \& Attia, S. (2012). Developing A Theory of Ubiquitous Marketing Research: Combining Ideology and Methodology of Marketing Research. Journal of American Science, 8(4), 534. http://www.americanscience.org.

Laughton, J. (1997). Darwinism and the Behavioral Theory of Socio-Cultural Evolution: An Analysis. American Journal of Sociology, 85(2), 288-302. https://doi.org/10.1086/227011

Levit, G. S., Hossfeld, U., \& Witt, U. (2011). Can Darwinism Be 'Generalized' and of What Use Would This Be? J Evol Econ., 21, 545-562. https://doi.org/10.1007/s00191-011-0235-3 
Lewontin, R. C. (1985). Adaptation. In R. Levins, \& R. C. Lewontin (Eds.), The Dialectical Biologist (pp. 65-84). Harvard University Press, Cambridge MA.

Marion, J. (2006). Research Note: Marketing Ideology and Criticism - Legitimacy and Legitimization. Marketing Theory, 6(2), 22-32. https://doi.org/10.1177/1470593106063985.

Marks, E. (2001). Information Darwinism chapter 6: The Impact of the Internet on Global Manufacturing, Marketing, and Supply Chain Management Work. Google Books. https://doi.org/10.1201/9781420000191.ch6

Matthews, R. C. O. (1984). Darwinism and Economic Change. Oxford University Economic Papers. https://doi.org/10.1093/oxfordjournals.oep.a041663

McCarthy, I. P. (2005). Toward a phylogenetic reconstruction of organizational life. Journal of Bioeconomics, 7(3), 271-307. https://doi.org/10.1007/s10818-005-5245-5

Mokyr, J. (2000). Evolutionary phenomena in technological change. In J. Ziman (Ed.), Technological Innovation as an Evolutionary Process (pp. 52-65). Cambridge: Cambridge University Press.

Mulcahy, K. V. (2003). Entrepreneurship or Cultural Darwinism? Privatization and American Culture Patronage. The Journal of Arts Management, Law and Society, 33(3), 165-184. https://doi.org/10.1080/10632920309597344

Murmann, J. P. (2003). Knowledge and Competitive Advantage: The Co-Evolution of Firms. Technology and National Institutions. Cambridge University Press, New York. https://doi.org/10.1017/CBO9780511510953

Nelson, R. R. (2006). Evolutionary Social Science and Universal Darwinism. J Evol Econ., 16, 491-510. https://doi.org/10.1007/s00191-006-0025-5

Nelson, R. R., \& Winter, S. G. (1982). An Evolutionary Theory of Economic Change. Belknap Press, Cambridge MA.

Nooteboom, B. (2006). Organization, evolution, cognition and dynamic capabilities. Center Discussion Paper, No. 2006-41, pp. 1-23. https://doi.org/10.2139/ssrn.962326

Nunan, D., \& Domenico, D. M. (2013). Market research and the ethics of big data. International Journal of Market Research, 55(4). https://doi.org/10.2501/IJMR-2013-015

Pelikan, P. (2011). Evolutionary developmental economics: how to generalize Darwinism fruitfully to help comprehend economic change. $J$ Evol Econ., 21, 341-366. https://doi.org/10.1007/s00191-010-0178-0

Rosenwald, P. J. (2004). Accountable Marketing: The Economics of Data-driven Marketing (pp. 239-58). Thomson, New York, NY.

Rubin, P. H. (2002). Darwinian Politics. New Brunswick: Rutgers University Press.

Saad, G., \& Gill, T. (2000). Applications of Evolutionary Psychology in Marketing. Psychology and Marketing, 17(12), 1005-1034. 
https://doi.org/10.1002/1520-6793(200012)17:12<1005::AID-MAR1>3.0.CO;2-H.

Sammut-Bonnici, T., \& Wensley, R. (2002). Darwinism, Probability and Complexity: Market-Based Organizational Transformation and Change Explained Through the Theories of

Evolution. Industrial Journal of Management Reviews, 4(3), 291-315. https://doi.org/10.1111/1468-2370.00088.

Satter, B. (2009). Darwinism and a Strategy for Survival in Business. London: Unicommoms Publishing Company.

Schubert, C. (2012). "Generalized Darwinism" and the Quest for an Evolutionary Theory of Policy-Making. Max Planck Institute of Economics, Germany.

Schubert, C. (2012). Is Novelty Always a good Thing? Towards an Evolutionary Welfare Economics. J Evol Econ., forthcoming. https://doi.org/10.1007/s00191-011-0257-x

Shadish, W. R., Cook, T. D., \& Campbell, D. T. (2002). Experimental and Quasi-Experimental Designs for Generalized Causal Inference (2nd ed., p. 267). Boston: Houghton Mifflin Company.

Stoelhorst, C. (2009). The Naturalist View of Universal Darwinism: An Application to the Evolutionary Theory of the Firm. In H. M. Geoffrey (Ed.), The Evolution of Economic Institutions: A Critical Reader (Cheltenham, UK: The European Association for Evolutionary Political Economy and Edward Elgar Publishing Limited Company).

Tadajewski, M., Chelekis, J., ... \& Moisander, J. (2015). The discourses of marketing and development: towards 'critical transformative marketing research'. Journal of Marketing Management, 30(17-18), 1728-1771. https://doi.org/10.1080/0267257X.2014.952660

Vollmer, C. (2010). Digital Darwinism in the New Marketing and Media Eco Systems. Google Books.

Vromen, J. (2007). Generalized Darwinism in Evolutionary Economics: The Devil is in the Details. Papers on Economics and Evolution. Max Planck Institute of Economics, Jena, Germany. ISSN 1430-4716

Vromen, J. (2008). Ontological issues in evolutionary economics: The Debate between Generalized Darwinism and the Continuity Hypothesis. Papers on Economics \& Evolution. Max Planck Institute of Economics, Jena Germany. http://hdl.handle.net/10419/31794.

Vromen, J. (2010). Heterogeneous Economic Evolution: A Different View on Darwinizing Evolutionary Economics, Papers on Economics and Evolution. Max Planck Institute of Economics, Jena, Germany.

Whitman, D. G. (1998). Hayek contra pangloss on evolutionary systems. Constitutional Political Economy, 9, 45-66. https://doi.org/10.1023/A:1009058615310

Wilson, D. S., \& Gowdy, J. (2010). The Relevance of Evolutionary Science for Economic Theory and Policy. White Paper for NSF SBE Program Initiative "Framing Research for 2020 and Beyond. 
Winter, S. (1964). Economic Natural Selection and the Theory of the Firm. Yale Econ Essays, 4, 225-272.

Witt, U. (2003). Economic Policy Making in Evolutionary Perspective. J Evol Econ., 13, 77-94. https://doi.org/10.4337/9781785365072.00022.

Witt, U. (2004). On the proper interpretation of 'evolution' in economics and its implications for production theory. Journal of Economic Methodology, 11, 125-146. https://doi.org/10.1080/13501780410001694091

Wolsky, A. (2010). A Hundred Years of Darwinism. Journal of Biology and Thought, 34(2), 165-184. https://doi.org/10.5840/thought195934211

\section{Appendix}

Appendix 1. table (1) expresses the most studies (Panels) with high impact, participants and remarks.

Appendix 2. Figure (1) the conceptual model.

Appendix 3. Table (2): The Proposed model's variables measurement scales.

\section{Copyright Disclaimer}

Copyright for this article is retained by the author(s), with first publication rights granted to the journal.

This is an open-access article distributed under the terms and conditions of the Creative Commons Attribution license (http://creativecommons.org/licenses/by/3.0/). 